\title{
Measurement of the high-field $Q$ drop in a high-purity large-grain niobium cavity for different oxidation processes
}

\author{
G. Ciovati, ${ }^{1, *}$ P. Kneisel, ${ }^{1}$ and A. Gurevich ${ }^{2}$ \\ ${ }^{1}$ Thomas Jefferson National Accelerator Facility, Newport News, Virginia 23606, USA \\ ${ }^{2}$ Applied Superconductivity Center, National High Magnetic Field Laboratory, Florida State University, \\ Tallahassee, Florida 32310, USA
}

(Received 8 May 2007; published 27 June 2007)

\begin{abstract}
The most challenging issue for understanding the performance of superconducting radio-frequency (rf) cavities made of high-purity (residual resistivity ratio $>200$ ) niobium is due to a sharp degradation (" $Q$-drop") of the cavity quality factor $Q_{0}\left(B_{p}\right)$ as the peak surface magnetic field $\left(B_{p}\right)$ exceeds about $90 \mathrm{mT}$, in the absence of field emission. In addition, a low-temperature $\left(100-140^{\circ} \mathrm{C}\right)$ in situ baking of the cavity was found to be beneficial in reducing the $Q$-drop. In this contribution, we present the results from a series of rf tests at 1.7 and $2.0 \mathrm{~K}$ on a single-cell cavity made of high-purity large (with area of the order of few $\mathrm{cm}^{2}$ ) grain niobium which underwent various oxidation processes, after initial buffered chemical polishing, such as anodization, baking in pure oxygen atmosphere, and baking in air up to $180^{\circ} \mathrm{C}$, with the objective of clearly identifying the role of oxygen and the oxide layer on the $Q$-drop. During each rf test a temperature mapping system allows measuring the local temperature rise of the cavity outer surface due to rf losses, which gives information about the losses location, their field dependence, and space distribution. The results confirmed that the depth affected by baking is about 20-30 nm from the surface and showed that the $Q$-drop did not reappear in a previously baked cavity by further baking at $120^{\circ} \mathrm{C}$ in pure oxygen atmosphere or in air up to $180^{\circ} \mathrm{C}$. These treatments increased the oxide thickness and oxygen concentration, measured on niobium samples which were processed with the cavity and were analyzed with transmission electron microscope and secondary ion mass spectroscopy. Nevertheless, the performance of the cavity after air baking at $180^{\circ} \mathrm{C}$ degraded significantly and the temperature maps showed high losses, uniformly distributed on the surface, which could be completely recovered only by a postpurification treatment at $1250^{\circ} \mathrm{C}$. A statistic of the position of the "hot spots" on the cavity surface showed that grain boundaries are not the preferred location. An interesting correlation was found between the $Q$-drop onset, the quench field, and the low-field energy gap, which supports the hypothesis of thermomagnetic instability governing the $Q$-drop and the baking effect.
\end{abstract}

DOI: 10.1103/PhysRevSTAB.10.062002

PACS numbers: 74.25.Nf, 84.40.-x, 81.65.Mq

\section{INTRODUCTION}

Superconducting elliptical rf cavities operating in the $\mathrm{TM}_{010}$ mode are commonly used to accelerate particle beams in a variety of accelerator facilities throughout the world. Niobium has been the material of choice for this application mainly due to its formability, relatively high critical temperature, and the highest lower critical magnetic fields among all superconductors. The significant improvements of surface cleaning techniques and control of contamination in recent years allowed one to reduce or eliminate field emission and to consistently improve the peak electric and magnetic fields on the cavity surface and thus the operational accelerating gradient. In the past year, a few single-cell cavities have achieved $B_{p}$-values close to the thermodynamic critical field of niobium [1]. Nevertheless, even field emission free superconducting cavities made of bulk niobium often show a severe degradation of the quality factor $Q_{0}$ as $B_{p}$ exceeds $\approx 90 \mathrm{mT}$. An effective

*gciovati@jlab.org way of reducing the $Q$-drop is a low-temperature $\left(100-140^{\circ} \mathrm{C}\right)$ in situ baking of the cavity in ultrahigh vacuum for several hours. A number of models have been proposed to explain the $Q$-drop and the baking effect: local quenches at sharp edges on the cavity surface, global thermal breakdown, field dependence of the energy gap, dielectric interface losses due to the oxide layer and grain boundary losses. These models all seem to contradict some of the experimental results, as described in the reviews in Ref. [2]. Understanding the origin of the $Q$-drop and the baking effect is of primary importance in order to reproducibly achieve high accelerating gradients in such largescale accelerators such as the proposed International Linear Collider (ILC) [3].

Measurements of low-field superconducting parameters such as the critical temperature $\left(T_{c}\right)$, the penetration depth at $0 \mathrm{~K}\left(\lambda_{0}\right)$ and the normal-electrons mean-free path $(l)$ suggested that oxygen diffusion is involved in the effect of low-temperature baking on the cavity performance $[4,5]$. Recently, a model based on reduced lower critical field due to higher interstitial oxygen near the surface has been 
refined to provide an explanation for the $Q$-drop and the baking effect [6]. In order to test the validity of this model, we tried to deliberately vary the oxygen content near the surface oxide layer by anodization, low-temperature baking in pure oxygen atmosphere, baking in air at higher temperatures, and in situ baking for shorter time. For this study we used a cavity made of large-grain niobium, based on the technology recently developed at Jefferson Lab [7], and we applied a temperature mapping system to identify the location, field dependence, and spatial distribution of the rf losses. Niobium samples have been treated together with the cavity and they have been analyzed with transmission electron microscope (TEM) and secondary ion mass spectroscopy (SIMS) to further understand the modifications of the oxide layer and of the impurities (oxygen and hydrogen) distribution near the surface due to such treatments.

The paper is organized as follows: a description of the experimental setup and of the typical cavity preparation procedures is given in Sec. II, while Sec. III presents the experimental results after anodization treatment, which converts the niobium metal into $\mathrm{Nb}_{2} \mathrm{O}_{5}$, therefore shifting the oxide/metal interface deeper inside the metal. Section IV shows the results on samples and cavity measurements after baking in pure oxygen atmosphere, in air at $120^{\circ} \mathrm{C}, 150^{\circ} \mathrm{C}$, and $180^{\circ} \mathrm{C}$, and after in situ baking for shorter time. The purpose of the tests was to change the oxygen concentration near the surface and to find a correlation with the $Q$-drop. Section V shows the cavity test results after degassing of hydrogen, which may have entered the niobium during the previous heat treatments, and after a postpurification with Ti to remove also oxygen and nitrogen. The analysis of the experimental data is presented in Sec. VI, where various aspects such as the medium field $Q$-slope, the relationship between the energy gap and the $Q$-drop, the field dependence and spatial distribution of hot-spots heating, hot spots at grain boundaries, and anomalous losses after $180^{\circ} \mathrm{C}$ air baking are discussed. Section VII provides an overall discussion of the experimental results, while conclusions are summarized in Sec. VIII.

\section{EXPERIMENTAL SETUP}

The cavity used for this experimental study has the same shape as the one used in the CEBAF accelerator [8]. The resonant frequency of the $\mathrm{TM}_{010}$ mode is at $1.47 \mathrm{GHz}$ for a center cell with beam pipe and the ratios of peak surface electric and magnetic fields to the accelerating field are $E_{p} / E_{\text {acc }}=1.78, B_{p} / E_{\text {acc }}=4.43 \mathrm{mT} /(\mathrm{MV} / \mathrm{m})$ as calculated with the SUPERFISH code [9]. The cavity was built by standard deep drawing and electron beam welding fabrication methods, starting from two $3.175 \mathrm{~mm}$ thick $\mathrm{Nb}$ sheets, which were saw-cut from a large-grain ingot made by Ningxia, China. The residual resistivity ratio (RRR) of the sheets was approximately 330 and the $\mathrm{Ta}$ content was less than 150 wppm, as specified by the manufacturer.

The standard cavity preparation for $\mathrm{rf}$ testing consists of the following.

(i) Ultrasonic degreasing for $20 \mathrm{~min}$.

(ii) Buffered chemical polishing (BCP) with a mixture of $\mathrm{HNO}_{3}(69 \%), \mathrm{HF}(49 \%), \mathrm{H}_{3} \mathrm{PO}_{4}(85 \%) 1: 1: 1$ or $1: 1: 2$ in volume at $25^{\circ} \mathrm{C}$ removing about $20 \mu \mathrm{m}$ of niobium from the inner cavity surface, in addition to initial removal of about $70 \mu \mathrm{m}$ after the cavity fabrication. The typical removal rates for freshly mixed acids are $\sim 3 \mu \mathrm{m} / \mathrm{min}$ and $\sim 2 \mu \mathrm{m} / \mathrm{min}$ for BCP 1:1:1 and 1:1:2, respectively.

(iii) High-pressure rinsing with ultrapure water at a pressure of 80 bar for $1 \mathrm{~h}$.

(iv) Drying for $4-16 \mathrm{~h}$ in class 10 clean room.

(v) Assembly of beam pipe flanges with input and output antenna and pump-out port using indium wire $1.52 \mathrm{~mm}$ thick as gasket in a class 10 clean room.

(vi) The cavity is attached to a test stand and evacuated to about $10^{-7}$ mbar prior to cooldown to $1.7 \mathrm{~K}$.

Before insertion in the vertical cryostat, a temperature mapping system consisting of an array of $576100 \Omega$ Allen-Bradley $5 \times 1.5 \mathrm{~mm}^{2}$ carbon resistors divided in 36 printed circuits boards spaced by $10^{\circ}$, is assembled on the cavity using Apiezon $\mathrm{N}$ grease. Details on the temperature mapping system can be found in Ref. [10]. The position of the thermometers on the cavity is identified by two numbers: the angular position from the reference mark on the cavity in degrees, 0 to 350 , and the vertical position, 1 to 16 , where 1 corresponds to the thermometer on the top beam tube near the cavity iris. There is no thermometer directly placed on the electron beam weld at the cavity equator, but there is one directly above it (No. 8) and one directly below (No. 9), about $8 \mathrm{~mm}$ from the equator line. The spacing between each resistor is approximately $1 \mathrm{~cm}$ along the meridian and from 0.8 to $1.6 \mathrm{~cm}$ along the azimuth, being larger at the equator. Figure 1 shows the temperature mapping system as assembled on a single-cell cavity.

During each rf test, the surface resistance $R_{s 0}$ at low field $\left(B_{p} \sim 10 \mathrm{mT}\right)$ is measured as a function of temperature between 4.3 and $1.7 \mathrm{~K}$; it is described by the following formula:

$$
R_{s 0}(T)=R_{\mathrm{BCS} 0}(T)+R_{\text {res }}^{0}
$$

where $R^{0}$ res is the temperature-independent residual resistance and $R_{\mathrm{BCS} 0}$ is the low-field Bardeen-Cooper-Schrieffer (BCS) surface resistance. The data are fitted to Eq. (1) with the code described in [11], based on the BCS surface impedance code developed by Halbritter [12]. The fit parameters are the mean-free path, $l$, the energy gap at $0 \mathrm{~K}, \Delta$, and the residual resistance. Here the critical temperature $T_{c}=9.25 \mathrm{~K}$, the London penetration depth $\lambda_{L}=42 \mathrm{~nm}$ and the coherence length $\xi_{0}=31 \mathrm{~nm}$ were used as the material parameters for $\mathrm{Nb}$. Measurements of 


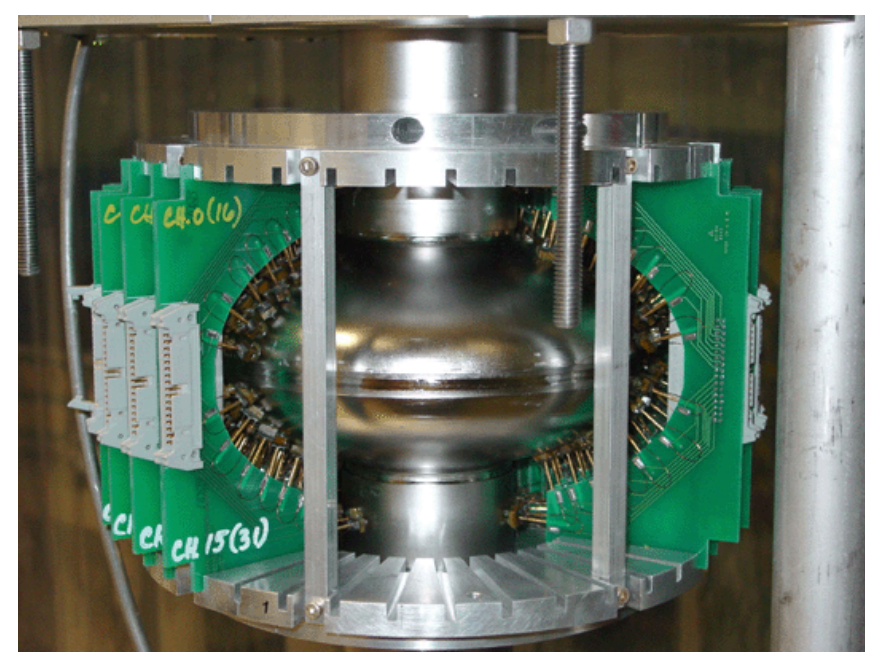

FIG. 1. (Color) Temperature mapping system, assembled on a single-cell cavity.

$Q_{0}$ vs $B_{p}$ and temperature maps at various field values are taken at 1.7 and $2.0 \mathrm{~K}$ using a phase-locked loop rf system. The typical measurements errors are 3\%-5\% for the surface field and $7 \%-12 \%$ for the quality factor. The temperature map shows the difference, $\Delta T(x, y)=$ $T(x, y)-T_{0}$, between the local temperature $T(x, y)$ measured by each resistor on the outer cavity surface and the He bath temperature $T_{0}$. Each resistor is calibrated between 4.3 and $1.7 \mathrm{~K}$ for every test; the He bath temperature in the cryostat is held constant by a pressure regulator during the $Q_{0}$ vs $B_{p}$ measurement and is measured by two calibrated germanium resistors near the cavity. The $\Delta T$ measured by each thermometer is related to the power dissipated per unit area, $d P / d A$, as follows:

$$
\Delta T=\eta\left(R_{K}+\frac{d}{\kappa}\right) \frac{d P}{d A}=K_{T} \frac{d P}{d A},
$$

where $\eta$ is the thermometer efficiency, $R_{K}$ is the Kapitza thermal resistance at the $\mathrm{Nb} / \mathrm{He}$ interface, $d$ is the cavity wall thickness, $\kappa$ is the thermal conductivity of $\mathrm{Nb}$ and $K_{T}$ represent the temperature response of a thermometer to a unit of uniform power flux. $d P / d A$ can be expressed as

$$
\frac{d P}{d A}=\frac{1}{2} R_{s}(H) H^{2}+\frac{1}{2} R_{s}^{E}\left(\frac{E}{Z_{0}}\right)^{2},
$$

where $R_{s}^{E}$ is a surface resistance due to dielectric losses, $Z_{0}$ is the impedance of vacuum, $E$ and $H$ are the local surface electric and magnetic field, respectively.

The low-temperature in situ baking is done by inserting the cavity, still assembled on the test stand and actively pumped, in an oven box. Nitrogen heated by a temperature controlled blower flows through the box to provide a rather uniform temperature across the cavity and the baking temperature is measured by a thermocouple directly attached to the cavity. The ramp-up and ramp-down time between $25^{\circ} \mathrm{C}$ and $120^{\circ} \mathrm{C}\left( \pm 2^{\circ} \mathrm{C}\right)$ is $2 \mathrm{~h}$.
Niobium samples of size $15 \mathrm{~mm} \times 12 \mathrm{~mm} \times 3 \mathrm{~mm}$ with RRR $>200$ have been processed with the singlecell cavity for some of the treatments (baking in 1 atm oxygen and baking in air). The samples have been analyzed with TEM and SIMS to obtain informations on the oxide layer thickness and the distribution of impurities such as oxygen, hydrogen, and carbon near the surface. The surface treatments of the samples before baking consisted of mechanical polishing with $40 \mu \mathrm{m}$ and $9 \mu \mathrm{m}$ sandpaper followed by about $80 \mu \mathrm{m}$ material removal by BCP.

One set of samples was analyzed at North Carolina State University (NCSU) using a CAMECA IMS-6F magnetic sector SIMS instrument with cesium primary beam and detection of negative secondary ions while the TEM measurements were made at Evans Analytical Group (EAG) in Raleigh, NC. Details about the measurement technique and parameters can be found in [13]. Another set of samples was analyzed at Jefferson Lab using a refurbished SIMS system [14] with argon primary ion beam and detection of positive secondary ions. The impact energy for $\mathrm{Ar}^{+}$was $3 \mathrm{keV}$ with normal incidence angle. This corresponds to approximately the same projected range as for the system at NCSU [15]. The argon beam was rastered over a $3 \mathrm{~mm} \times 2.5 \mathrm{~mm}$ area (with current density $85 \mu \mathrm{A} / \mathrm{cm}^{2}$ ) and the sputtering rate is $\sim 2.5 \mathrm{~nm} / \mathrm{min}$. The base pressure of the SIMS chamber was $\sim 7.5 \times 10^{-9}$ Torr and the measurements were taken on at least two sites for each sample.

\section{ANODIZATION}

Anodization was commonly used for the preparation of niobium cavities in the 1970s [16], allowing one to elec-

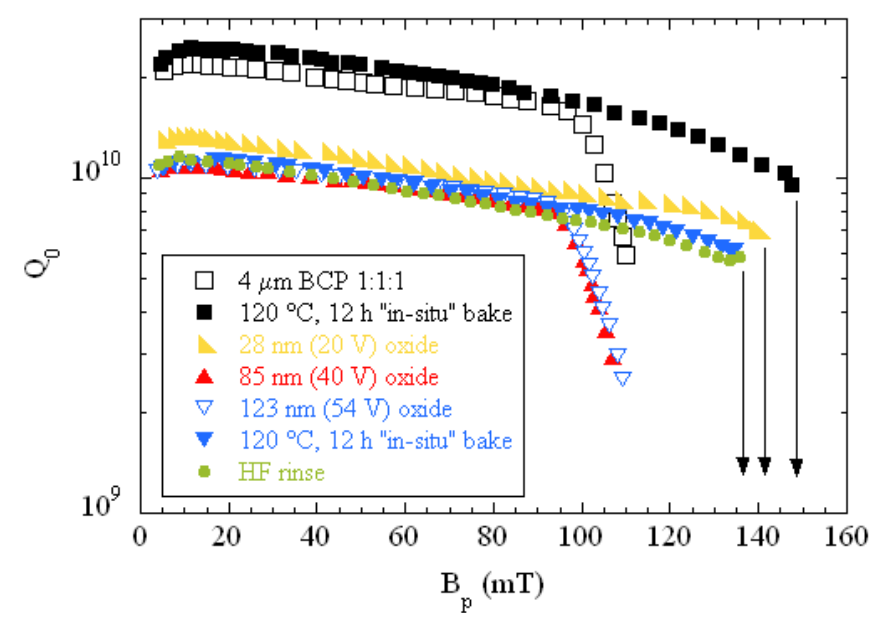

FIG. 2. (Color) $Q_{0}$ vs $B_{p}$ measured at $1.7 \mathrm{~K}$ for several surface treatments. The $Q$-drop reoccurs at the same field as after the BCP treatment by anodizing the surface of the baked cavity at $40 \mathrm{~V}$. The vertical arrows indicate the quench field. An increase of $R^{0}$ res was observed as a consequence of field emission loading starting at $E_{p}=45 \mathrm{MV} / \mathrm{m}\left(B_{p}=110 \mathrm{mT}\right)$ in the test after the first in situ bake and caused a reduction of the low-field $Q_{0}$ in the subsequent tests. 
trochemically grow an amorphous $\mathrm{Nb}_{2} \mathrm{O}_{5}$ film whose thickness depends mainly on the voltage applied between the cavity (anode) and a cathode. For this study, the cavity is filled with $\mathrm{NH}_{4} \mathrm{OH}(15 \%)$, and a constant voltage is applied between the cavity and a $\mathrm{Nb}$ rod inserted in the cavity. The current is limited to about $1 \mathrm{~A}\left(\sim 1 \mathrm{~mA} / \mathrm{cm}^{2}\right)$ and decays exponentially with time as the oxide thickens. The power supply is switched off when the current drops to about $100 \mathrm{~mA}$. In these conditions we expect an oxide thickness corresponding to about $2 \mathrm{~nm} / \mathrm{V}$ [17]. By anod- izing successively at increasing voltages a cavity which was previously in situ baked, we convert some of the niobium into oxide until eventually the $Q$-drop may reoccur. This could give some indications of the depth affected by the low-temperature baking. This experiment was recently done at Cornell University [18] on two polycrystalline $\mathrm{Nb}$ single cells treated by $\mathrm{BCP}$ and electropolishing. After the cavities were baked at $100^{\circ} \mathrm{C}$ for $48 \mathrm{~h}$, the $Q$-drop reoccurred by anodizing at $30 \mathrm{~V}$. The following paragraphs describe our experimental results.
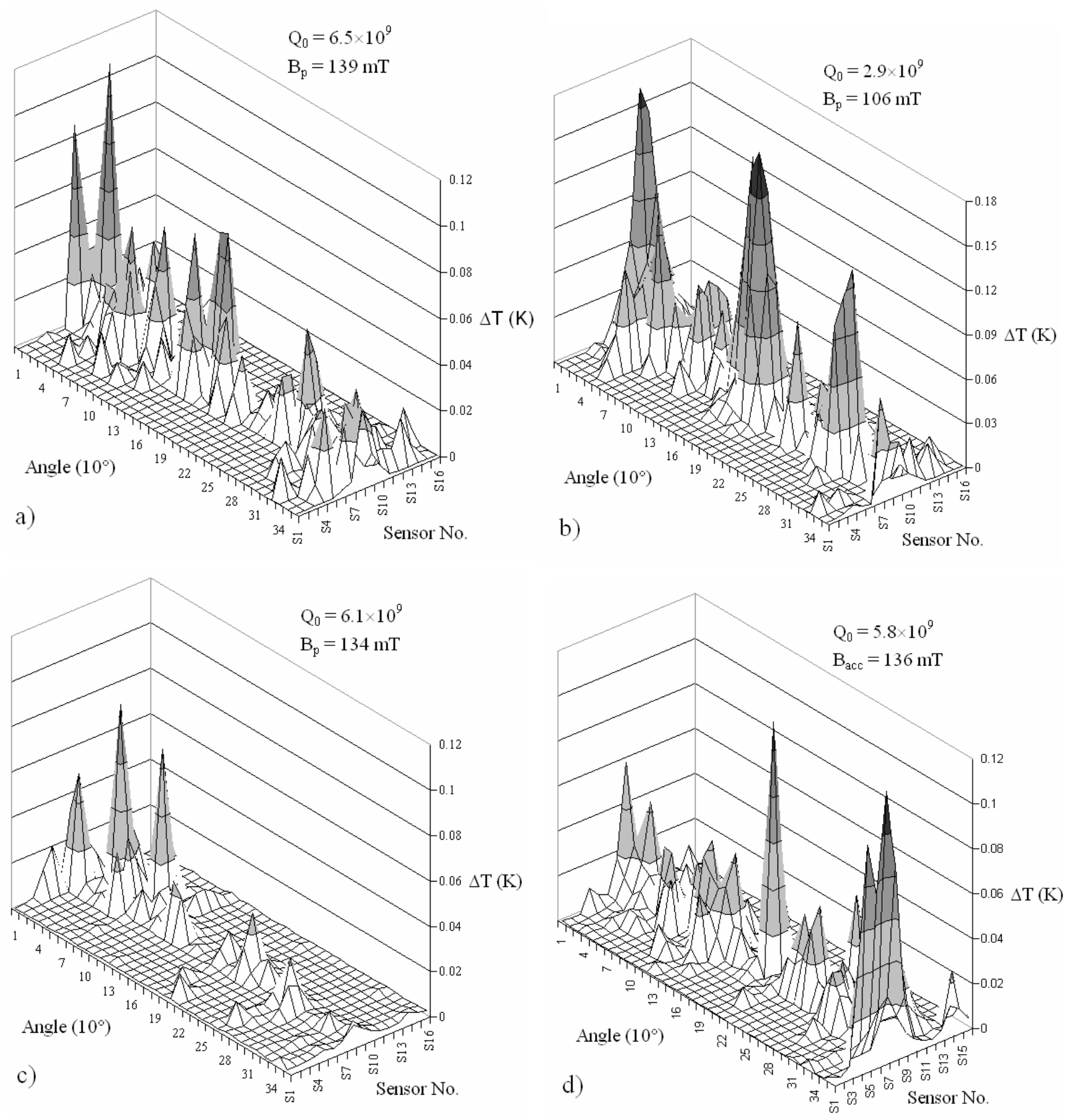

FIG. 3. Temperature maps at the He bath temperature of $1.7 \mathrm{~K}$ at the highest rf field achieved after $20 \mathrm{~V}$ anodization (28 nm thick oxide) (a), $40 \mathrm{~V}$ anodization ( $85 \mathrm{~nm}$ thick oxide) (b), $120^{\circ} \mathrm{C} 12 \mathrm{~h}$ in situ baking after anodization (c), and HF rinse (d). Three major hot spots in (b) cause a $Q$-drop and they are greatly reduced by the low-temperature baking in (c). Note the different $\Delta T$ scale. 
After fabrication, the cavity was chemically etched with BCP 1:1:1 removing approximately $70 \mu \mathrm{m}$, then was postpurified in a Ti box, used as solid state getter, in a vacuum furnace at $1250^{\circ} \mathrm{C}$ for $3 \mathrm{~h}$. The cavity went through the following series of surface preparations and $\mathrm{rf}$ tests.

(i) $\sim 30 \mu \mathrm{m}$ removal by BCP $1: 1: 1$. The $Q_{0}\left(B_{p}\right)$ curve showed $Q$-drop starting at $B_{p} \cong 124 \mathrm{mT}$.

(ii) $120^{\circ} \mathrm{C}$ in situ baking for $20 \mathrm{~h}$. The $Q$-drop was eliminated and the cavity quenched at $B_{p}=162 \mathrm{mT}$.

(iii) $20 \mathrm{~V}$ anodization. The cavity quenched at $B_{p}=$ $161 \mathrm{mT}$ with no $Q$-drop.

(iv) $30 \mathrm{~V}$ anodization. The $Q$-drop started at $B_{p}=$ $157 \mathrm{mT}$ and the cavity quenched at $B_{p}=167 \mathrm{mT}$.

(v) $40 \mathrm{~V}$ anodization. The $Q$-drop started at $B_{p} \cong$ $129 \mathrm{mT}$.

(vi) $55 \mathrm{~V}$ anodization. The $Q$-drop started at $B_{p} \cong$ $125 \mathrm{mT}$.

(vii) $120^{\circ} \mathrm{C}$ in situ baking for $12 \mathrm{~h}$. The $Q$-drop was eliminated and the cavity quenched at $B_{p}=162 \mathrm{mT}$.

(viii) HF (49\%) rinse for $7 \mathrm{~min}$ to remove the anodic oxide layer. The cavity quenched at $B_{p}=152 \mathrm{mT}$ with no $Q$-drop.

Some field emission was evident only after $40 \mathrm{~V}$ anodization. The cavity exhibited no field emission after an additional high-pressure rinse but $R_{\text {res }}^{0}$ was higher by about $10 \mathrm{n} \Omega$. This first series of tests was done at $2.0 \mathrm{~K}$ without temperature mapping.

A new series of test was repeated at 1.7 and $2.0 \mathrm{~K}$ in the same sequence as the previous one and the $Q_{0}$ vs $B_{p}$ curves at $1.7 \mathrm{~K}$ are shown in Fig. 2. The current vs time was measured during each anodization step, which allowed us to calculate the total charge transfer, and therefore the thickness of the $\mathrm{Nb}_{2} \mathrm{O}_{5}$ film (indicated between parentheses in the legend of Fig. 2), using Faraday's law. The quench field after baking was 5\%-12\% lower than in the first series of tests. Some field emission was present only in the test after the first in situ baking, starting at $E_{p}=$ $45 \mathrm{MV} / \mathrm{m}$. After attempting without success to reduce the field emission by rf processing, the surface resistance at low field became higher than during the initial power rise, and corresponded to an increase of the residual resistance by about $7.5 \mathrm{n} \Omega$, which reduced the $Q_{0}$ at low field in the subsequent tests also. This effect, which had been observed in the past [19], was related to the radiation damage of the oxide layer [20]. Temperature maps for some of the tests, taken at the highest field achieved, are shown in Fig. 3: the presence of the $Q$-drop is associated with few "hot spots" near the cavity equator. Only the hot spot at the position 180-9 was present in all tests limited by $Q$-drop (after $4 \mu \mathrm{m}$ BCP 1:1:1, $40 \mathrm{~V}$ anodization and $54 \mathrm{~V}$ anodization) and all of the hot spots were eliminated, or their intensity was strongly reduced, by baking. The quench location changed from position 150-8, after the first baking, to position $180-8$ after $20 \mathrm{~V}$ anodization and remained the same after the second bake and HF rinse.
The results from both series of $\mathrm{rf}$ tests are consistent with each other and with the results obtained at Cornell in showing that an anodic oxide layer $\sim 60 \mathrm{~nm}$ thick causes the $Q$-drop to reoccur and by further anodizing to $\sim 85 \mathrm{~nm}$ the onset of the $Q$-drop is reduced to the same value as after BCP. The in situ baking applied to a cavity with a $\sim 123 \mathrm{~nm}$ thick oxide is still effective in eliminating the $Q$-drop, up to a quench field of $162 \mathrm{mT}$. By rinsing with $\mathrm{HF}$, the existing $\mathrm{Nb}_{2} \mathrm{O}_{5}$ layer is dissolved and a new, thinner $(\sim 5 \mathrm{~nm})$ one is grown by rinsing the cavity with ultrapure water. This treatment on a fine-grain cavity, electropolished and baked, was first done at Saclay [21] and our results concur with theirs in showing that the $Q$-drop is not restored up to a quench field of $165 \mathrm{mT}$, in their case, and of $152 \mathrm{mT}$ in our cavity, although some additional losses can be seen in Fig. 3(d).

Results from the low-field measurements of $R^{0}$ res and $\Delta / k T_{c}$ ( $k$ is the Boltzmann constant) from both series of tests are shown in Figs. 4 and 5, respectively. Anodization up to $123 \mathrm{~nm}$ thick oxide increases the residual resistance by $1-4 \mathrm{n} \Omega$ while the ratio $\Delta / k T_{c}$ is progressively reduced down to similar values obtained after BCP treatment. In situ baking at $120^{\circ} \mathrm{C}$ for $12-20 \mathrm{~h}$ increases $R^{0}{ }_{\text {res }}$ by $3-5 \mathrm{n} \Omega$ while increasing $\Delta / k T_{c}$ by $7 \%-10 \%$. HF rinse does not change $\Delta / k T_{c}$ significantly but reduces $R_{\text {res }}^{0}$ by 3-15 $\mathrm{n} \Omega$. "In- situ" baking at $120^{\circ} \mathrm{C}$ reduces also the BCS surface resistance at $4.3 \mathrm{~K}$ by about $35 \%$ ( $12 \mathrm{~h}$ bake) and by $44 \%$ when baking for longer time $(20 \mathrm{~h})$. The mean-free path was about $50 \mathrm{~nm}$ after BCP but baking reduces it down to about $16 \mathrm{~nm}$. Anodization up to $123 \mathrm{~nm}$ thick oxide increases $l$ up to about $40 \mathrm{~nm}$ and no significant changes are observed due to HF rinse. The variations of $R_{\text {res }}^{0}, R_{\mathrm{BCS} 0}, l$ and $\Delta / k T_{c}$ observed after in situ baking and HF rinse are consistent with previous results at Saclay [3] and Jefferson Lab [4].

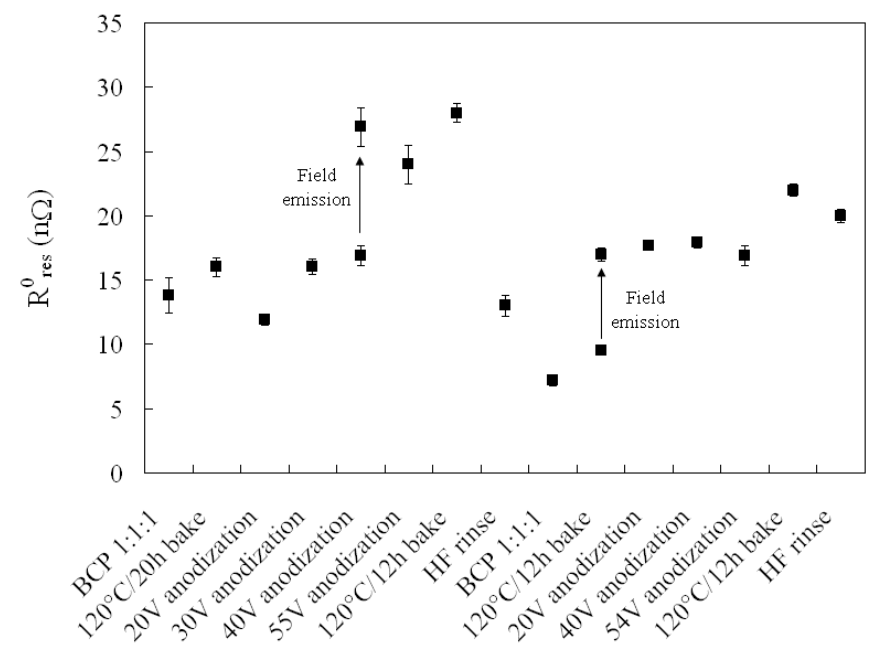

FIG. 4. Residual resistance as a function of surface treatment during the two series of anodization tests. 


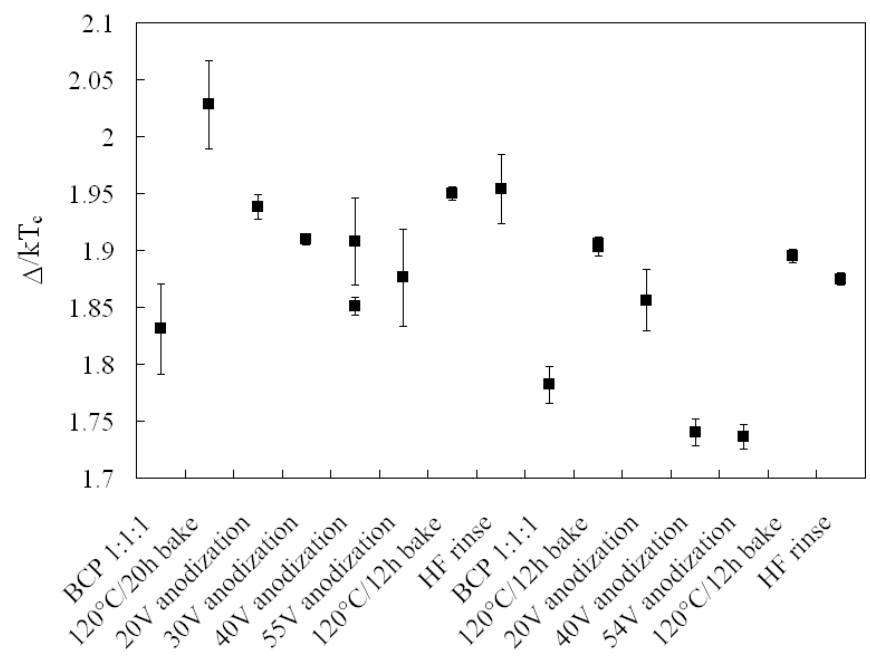

FIG. 5. $\Delta / k T_{c}$ as a function of surface treatment during the two series of anodization tests.

\section{BAKING IN PURE OXYGEN ATMOSPHERE AND IN AIR}

\section{A. Cavity test results}

\section{Baking in pure oxygen atmosphere}

In order to further investigate the role of oxygen in causing the $Q$-drop we baked the cavity at $120^{\circ} \mathrm{C}$ in $1 \mathrm{~atm}$ of pure oxygen as follows: the cavity was removed from the vertical test stand, placed inside the baking oven, and connected to a vacuum line. Two fine-grain $(50 \times$ $50 \mu \mathrm{m}^{2}$ average grain size) $\mathrm{Nb}$ samples were also inserted. The cavity was evacuated to $6 \times 10^{-9}$ mbar (water was the main residual gas), backfilled with research grade (99.9969\% purity) oxygen up to 1 atm, and baked for $12 \mathrm{~h}$. A relief valve limited the oxygen pressure to $1.1 \mathrm{~atm}$ during baking. Afterwards the $\mathrm{Nb}$ samples were stored in air while the cavity was high-pressure rinsed, reassembled, evacuated, the temperature mapping system was assembled, and the test stand with the cavity was finally inserted in the vertical cryostat for the rf test. There was no significant change of performance from the previous rf test (HF rinse) both at 1.7 and $2.0 \mathrm{~K}$ : the residual resistance was unchanged, $\Delta / k T_{c}$ and quench field (which occurred at the same location) increased by about $2 \%$ and $5 \%$, respectively. The temperature map at the breakdown field also did not show significant variations from the test before. Then the experiment was repeated and the duration of baking was increased to $48 \mathrm{~h}$. As a result, $\Delta / k T_{c}$ increased by about $3 \%$, the quench field and location did not change. The $Q_{0}$ vs $B_{p}$ plot at $1.7 \mathrm{~K}$ after baking for $48 \mathrm{~h}$ is shown in Fig. 6 while the temperature map at $142 \mathrm{mT}$ is shown in Fig. 7(a).

\section{Baking in air at higher temperature}

The results from the oxygen baking tests suggested that the heating temperature may have not been high enough to

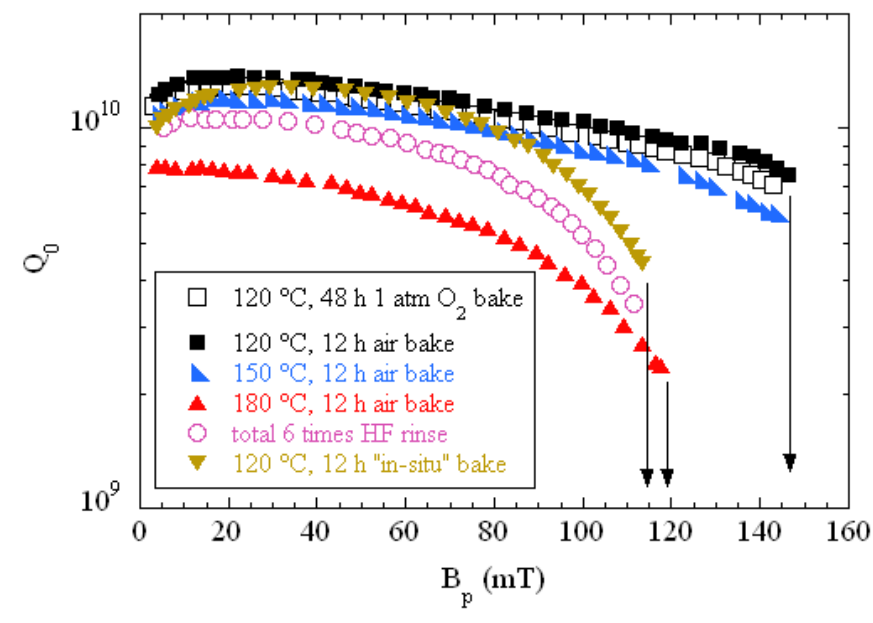

FIG. 6. (Color) $Q_{0}$ vs $B_{p}$ measured at $1.7 \mathrm{~K}$ for several baking conditions. Baking at $180^{\circ} \mathrm{C}$ in air caused a significant degradation of $Q_{0}$ and of the quench field which were not recovered by multiple $\mathrm{HF}$ rinses and by in situ baking at $120^{\circ} \mathrm{C}$.

diffuse oxygen through the oxide into the niobium. Therefore we decided to bake the cavity in air as follows: the cavity was removed from the test stand, the beam pipes were opened, and the cavity was degreased. The cavity was then rinsed with ultrapure water and, while still wet, two niobium disks were clamped to close the beam pipe openings. Two fine-grain niobium samples were placed on the bottom disk inside the cavity. The cavity was set vertically in a frame inside the oven and baked. After baking, the cavity was degreased, high-pressure rinsed, reassembled, evacuated, the temperature mapping system was assembled, and the test stand with the cavity was finally inserted in the vertical cryostat for the rf test. This baking procedure was repeated for the baking temperatures of $120^{\circ} \mathrm{C}, 150^{\circ} \mathrm{C}$, and $180^{\circ} \mathrm{C}$ for $12 \mathrm{~h}$. The rf tests results, shown in Fig. 6, are summarized as follows.

(i) No significant variations of $\Delta / k T_{c}, l, R^{0}{ }_{\text {res }}$, and quench field and location after baking at $120^{\circ} \mathrm{C}$ have been observed. The temperature map at the highest field [Fig. 7(b)] revealed some additional losses occurring also in the high electric field regions.

(ii) Baking at $150^{\circ} \mathrm{C}$ caused an increase of $R^{0}$ res by about $3 \mathrm{n} \Omega$, a decrease of $\Delta / k T_{c}$ by about $3 \%$, and no change of quench field $(\sim 145 \mathrm{mT})$ or of its location (180-9). Nevertheless, there was some degradation of $Q_{0}$ at high field due to additional hot spots, more or less uniformly distributed over the cavity area, including the irises.

(iii) Baking at $180^{\circ} \mathrm{C}$ caused an increase of $R_{\text {res }}^{0}$ by about $8 \mathrm{n} \Omega$, a significant decrease of $\Delta / k T_{c}(\sim 11 \%)$, and of the quench field $(\sim 18 \%)$ at the same location. The temperature map at $B_{p}=117 \mathrm{mT}$ [Fig. 7(c)] showed a significant heating of the whole cavity surface. The power dissipated at the highest field was $\sim 40 \mathrm{~W}$ and the temperature of the He bath near the cavity increased by $\sim 0.2 \mathrm{~K}$. The $Q_{0}$ vs $B_{p}$ curve shows a quadraticlike degradation of $Q_{0}$, not as sharp as for the $Q$-drop. The low-field 

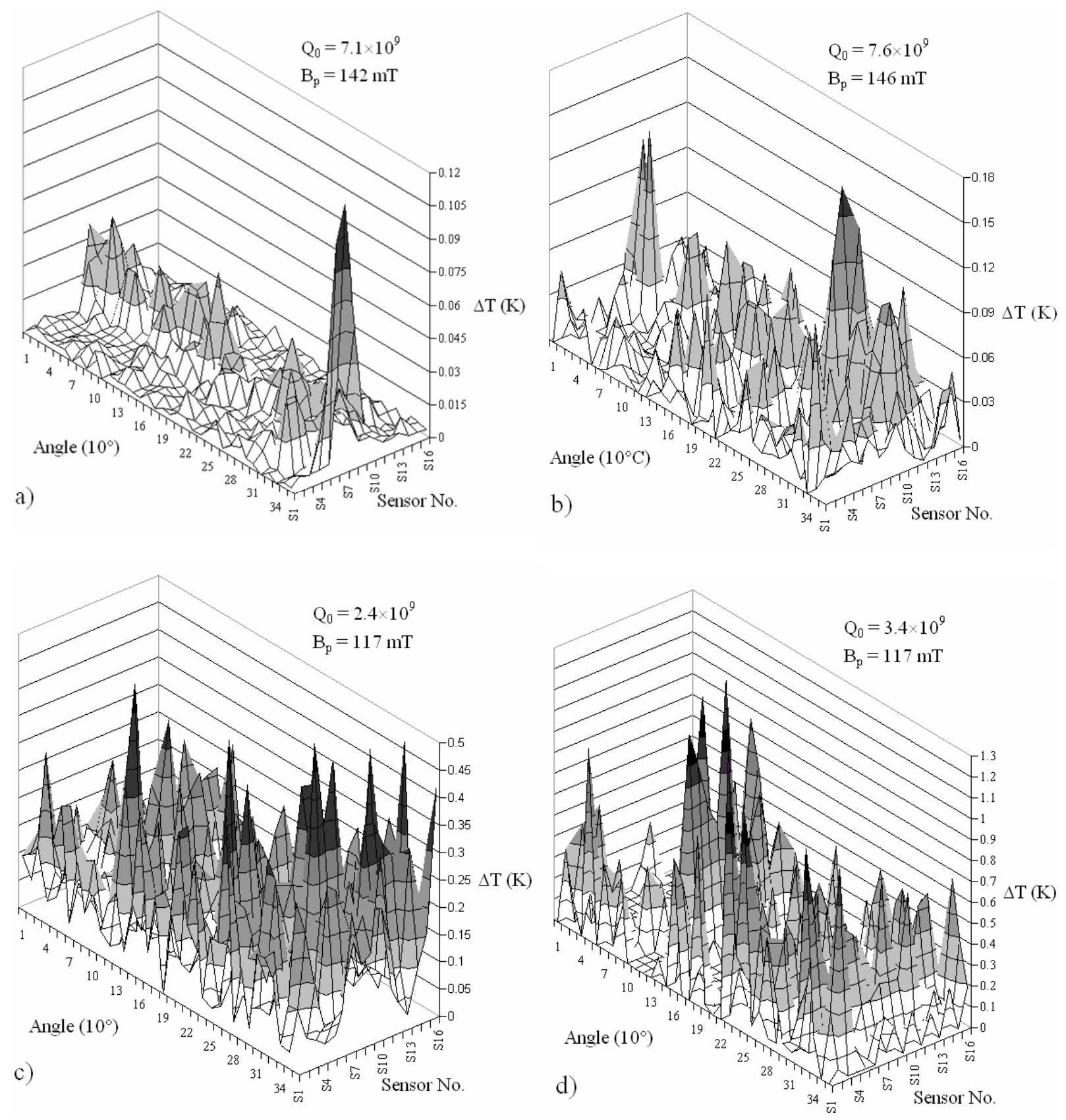

FIG. 7. Temperature maps at the He bath temperature of $1.7 \mathrm{~K}$ at the highest rf field achieved after $120^{\circ} \mathrm{C} 48 \mathrm{~h}$ baking in 1 atm of oxygen (a), $120^{\circ} \mathrm{C} 12 \mathrm{~h}$ baking in air (b), $180^{\circ} \mathrm{C} 12 \mathrm{~h}$ baking in air (c), and a total of 6 times HF rinses (d). Heating of the whole cavity surface and hot spots at the irises (high electric field area) occur after baking at $180^{\circ} \mathrm{C}$. The higher $\Delta T$ in (c) and (d) is due to a higher thermal response of the thermometers, possibly due to an increase of Kapitza resistance. Note the different $\Delta T$ scales.

BCS surface resistance at $4.3 \mathrm{~K}$ increased up to the same values as after a chemical etch, due to the reduction of the gap parameter.

In order to determine whether the additional losses were due to the oxide layer, the cavity was rinsed with $\mathrm{HF}(49 \%)$ and reoxidized in water for a total of 6 times. In a first attempt, the cavity was rinsed with HF for 5 min then filled with ultrapure water for $1 \mathrm{~h}$, followed by a second HF rinse and then prepared for the rf test using the standard proce- dure of Sec. II, starting with high-pressure rinse. The test results showed a reduction of $R^{0}$ res down to the value prior to air baking $(\sim 20 \mathrm{n} \Omega)$ and of the intensity of some hot spots, but no change in the quench field and location and in the $Q_{0}$ vs $B_{p}$ dependence. The HF rinse procedure was repeated for four more times and the only change was the location of the quench (from 180-9 to 130-12) and of some of the hot spots. The $Q_{0}$ vs $B_{p}$ curve after the six HF rinses is shown in Fig. 6 and the temperature map at 


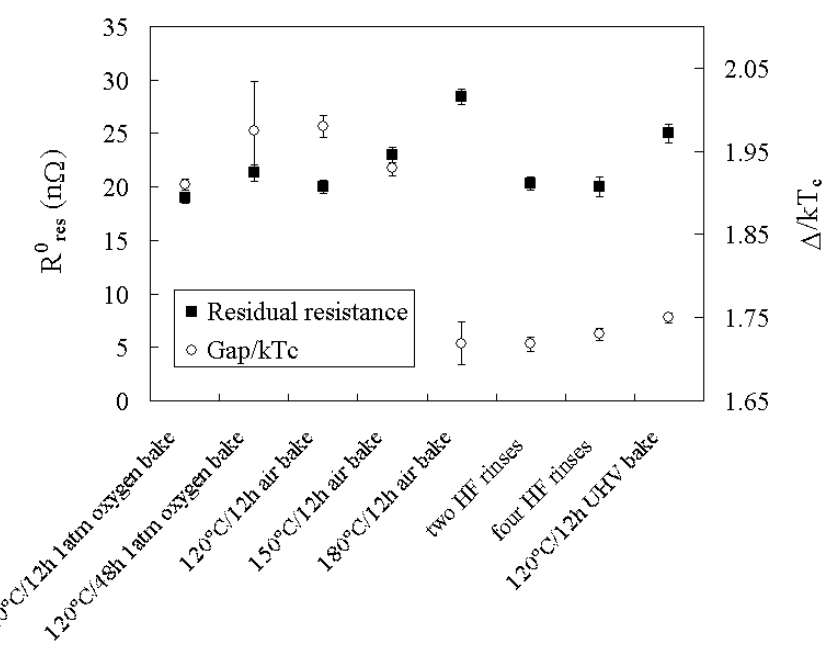

FIG. 8. $\quad R^{0}{ }_{\text {res }}$ and $\Delta / k T_{c}$ for different baking conditions and $\mathrm{HF}$ rinses.

$B_{p}=117 \mathrm{mT}$ is shown in Fig. 7(d). Although the additional losses introduced by the air baking at higher temperature did not have the same field dependence as for the $Q$-drop, we applied the standard in situ UHV baking procedure at $120^{\circ} \mathrm{C}$ for $12 \mathrm{~h}$ to investigate whether they could also be reduced, but we did not succeed (The $Q_{0}$ vs $B_{p}$ curve is shown in Fig. 6). We tried to evaluate whether enough hydrogen from the wet surface could penetrate through the oxide layer to cause the so-called $Q$-disease [22] during the baking at $180^{\circ} \mathrm{C}$. In order to do that, we hold the cavity in the cryostat at a temperature of $100 \mathrm{~K}$ for $40 \mathrm{~h}$, which would allow the precipitation of a lossy niobium hydride phase, if the hydrogen concentration was above about 5 wppm. The subsequent $\mathrm{rf}$ tests at 1.7 and $2.0 \mathrm{~K}$ did not show any reduction of the low-field $Q_{0}$ nor any variation of the $Q_{0}$ vs $B_{p}$ dependence from the previous test. Figure 8 shows the variations of $R^{0}{ }_{\text {res }}$ and $\Delta / k T_{c}$ for the various tests discussed in this section.

\section{Effect of baking duration}

We also investigated the evolution of the hot spots by in situ baking for shorter durations. The inner cavity surface was etched by BCP $1: 1: 1$, removing about $30 \mu \mathrm{m}$ of material, and the rf test showed reduced residual losses $\left(R_{\text {res }}^{0}=11 \mathrm{n} \Omega\right)$ and $Q$-drop starting at $B_{p} \cong 104 \mathrm{mT}$. A much higher number of hot spots than typically found, for example, in Fig. 3(b), was observed from the temperature maps and their location is scattered throughout the surface, even at the iris. The cavity was checked again for $Q$-disease, by holding it between $100-140 \mathrm{~K}$ for $15 \mathrm{~h}$ with a negative result. Surprisingly, in situ baking at $120^{\circ} \mathrm{C}$ for only $3 \mathrm{~h}$ was sufficient to reduce most of the hot spots up to a quench field of $142 \mathrm{mT}$. The surface was reset by removal of $17 \mu \mathrm{m}$ of material by BCP 1:1:1. The residual resistance decreased significantly $\left(R_{\text {res }}^{0}=5 \mathrm{n} \Omega\right)$, the $Q$-drop started at $B_{p} \cong 100 \mathrm{mT}$ with fewer hot spots.

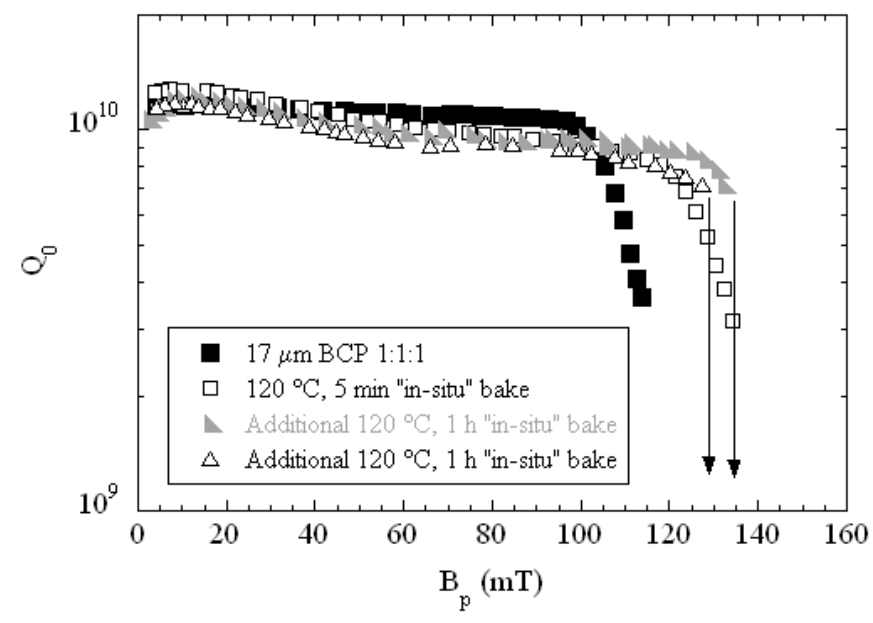

FIG. 9. $Q_{0}$ vs $B_{p}$ measured at $2.0 \mathrm{~K}$ after etching with BCP 1:1:1 followed by additional in situ baking at $120^{\circ} \mathrm{C}$.

The cavity was in situ baked at $120^{\circ} \mathrm{C}$ for only $5 \mathrm{~min}$ (the temperature ramp-up/-down time is $2 \mathrm{~h}$ ) and the $Q$-drop onset shifted to $118 \mathrm{mT}$. The cavity was baked for an additional hour and the $Q$-drop was reduced up to the quench field (133 mT, location 180-9). No improvement was obtained after one more $1 \mathrm{~h}$ long bake, as the quench field was $127 \mathrm{mT}$. The $Q_{0}$ vs $B_{p}$ curves at $2.0 \mathrm{~K}$ for this series of baking tests is shown in Fig. 9.

We also verified whether baking in air at $120^{\circ} \mathrm{C}$ would give similar improvement of the $Q$-drop as the in situ baking, in ultrahigh vacuum conditions. The baseline $\mathrm{rf}$ test was done after removal of $17 \mu \mathrm{m}$ of material by BCP $1: 1: 1$, resulting in $Q$-drop starting at $B_{p} \cong 105 \mathrm{mT}$. After baking the opened cavity in air at $120^{\circ} \mathrm{C}$ for $3 \mathrm{~h}$, followed by high-pressure rinse, the cavity quenched at $140 \mathrm{mT}$, similar to the value obtained after in situ bake, although the $Q_{0}$ degraded at high field and $\mathrm{rf}$ losses were present in

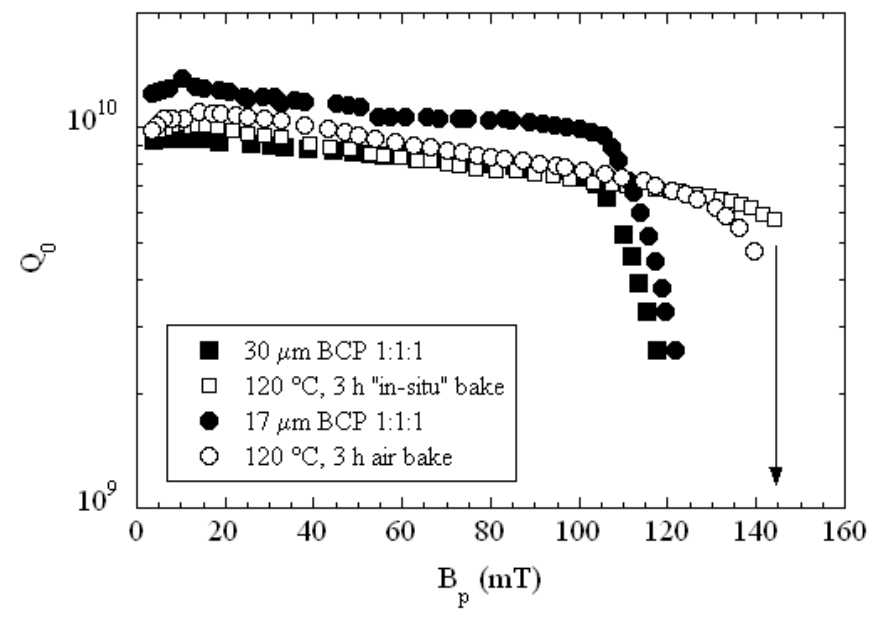

FIG. 10. $Q_{0}$ vs $B_{p}$ measured at $2.0 \mathrm{~K}$ after etching by $\mathrm{BCP}$ 1:1:1 followed by in situ baking at $120^{\circ} \mathrm{C}$ for $3 \mathrm{~h}$ and after another chemical etch followed by air baking with the same parameters as for the in situ one. 
larger portions of the cavity surface. The residual resistance also increased more by air baking ( $7 \mathrm{n} \Omega$ versus $2 \mathrm{n} \Omega$ increase). The $Q_{0}$ vs $B_{p}$ curves at $2.0 \mathrm{~K}$ for the baseline tests and after baking at $120^{\circ} \mathrm{C}$ for $3 \mathrm{~h}$ in air and in UHV are shown in Fig. 10.

\section{Effect of the outer surface condition}

It was noticed that the thermometers' thermal response coefficient $K_{T}$ in Eq. (2), obtained from a fit of the lowfield dissipated power from rf measurements with the power dissipated on the cavity walls from the temperature maps, ${ }^{1}$ increased progressively with higher baking temperature by up to more than 1 order of magnitude. This may have been caused by an increase of Kapitza resistance due to oxidation, as the outer surface of the cavity looked dark gray after baking at $180^{\circ} \mathrm{C}$, despite the nitrogen atmosphere on the outside.

Typically, no chemical treatment of the outer cavity surface was applied. However, during the preparation for the baseline test, shown in Fig. 9, before baking, the outer surface of the cavity was etched for about $30 \mathrm{~s}$ with BCP $1: 1: 1$, making it appear shiny, in addition to $17 \mu \mathrm{m}$ removed from the inside surface. The $Q_{0}$ vs $B_{p}$ curve showed similar behavior as after the previous baseline test, shown in Fig. 10, when $30 \mu \mathrm{m}$ were removed from the inside surface only. Therefore the short chemical etch of the outer surface did not seem to have a significant impact on the cavity performance, although a reduction of $K_{T}$ was obtained.

\section{B. Niobium samples results}

The results from the TEM measurements of the oxide thickness on the fine-grain polycrystalline $\mathrm{Nb}$ samples for different baking treatments are shown in Table I. The sample treatments prior to baking are described in Sec. II. Figure 11 shows the TEM micrograph for the sample W3. There was no significant increase of the oxide thickness for the sample baked at $120^{\circ} \mathrm{C}$ for $12 \mathrm{~h}$ in $1 \mathrm{~atm}$ of oxygen with respect to the reference sample, while the increase was $0.3 \pm 0.1 \mathrm{~nm}$ for the second oxygen bake, for longer time $(48 \mathrm{~h})$. More significant increase, up to $3.3 \pm$ $0.2 \mathrm{~nm}$ is observed after air baking at higher temperatures. The TEM pictures showed no identifiable suboxide regions.

The oxygen and hydrogen SIMS depth profiling relative to niobium for the reference sample and for the samples W1, W2, and W3 are shown in Figs. 12 and 13, respectively. Carbon is present mainly at the surface. Higher oxygen counts over a larger depth than in the reference sample was found in all samples (including $\mathrm{O} 2$ and $\mathrm{O} 5$ ). The exponential decrease in $\mathrm{O}^{-}$ion intensity after sputter-

\footnotetext{
${ }^{1}$ The efficiency of the thermometers is assumed to be the same for all of them, the surface resistance is assumed to be field independent, and dielectric losses are neglected.
}

TABLE I. Labels, baking treatments, and oxide thickness TEM measurements for the fine-grain niobium samples treated with the single-cell cavity.

\begin{tabular}{lcc}
\hline \hline Label & Baking treatment & Oxide thickness $(\mathrm{nm})$ \\
\hline REF & None & $6.8 \pm 0.1$ \\
O2 & $120^{\circ} \mathrm{C}, 12 \mathrm{~h}$ bake in 1 atm $\mathrm{O}_{2}$ & $6.7 \pm 0.2$ \\
O5 & $120^{\circ} \mathrm{C}, 48 \mathrm{~h}$ bake in 1 atm $\mathrm{O}_{2}$ & $7.1 \pm 0.1$ \\
W2 & $120^{\circ} \mathrm{C}, 12 \mathrm{~h}$ air bake & $8.3 \pm 0.3$ \\
W1 & $120^{\circ} \mathrm{C}+150^{\circ} \mathrm{C}, 12 \mathrm{~h}$ air bake & $8.7 \pm 0.2$ \\
W3 & $180^{\circ} \mathrm{C}, 12 \mathrm{~h}$ air bake & $10.1 \pm 0.2$ \\
\hline \hline
\end{tabular}

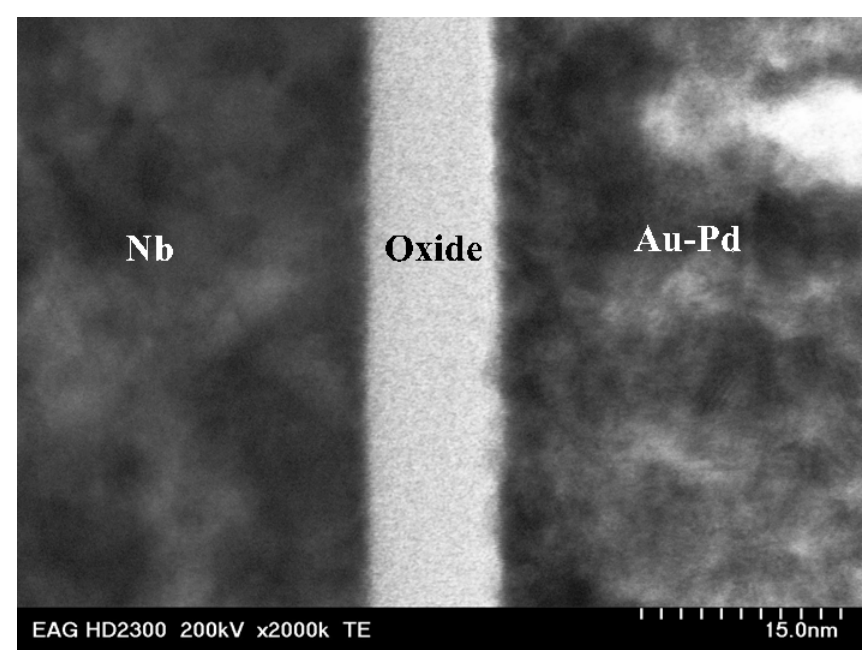

FIG. 11. TEM cross-section micrograph of the sample W3 baked in air at $180^{\circ} \mathrm{C}$ for $12 \mathrm{~h}$, showing a distinct oxide layer on the $\mathrm{Nb}$ surface.

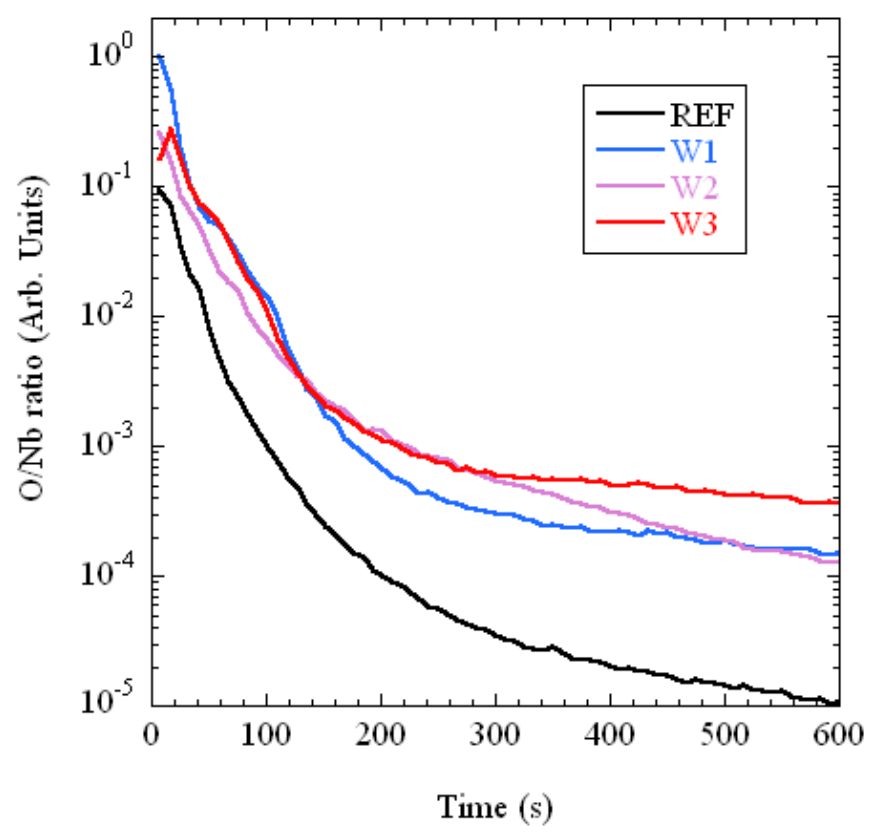

FIG. 12. (Color) SIMS oxygen depth profiling done at NCSU for samples baked at different temperatures. The sample treatments are indicated in Table I. 


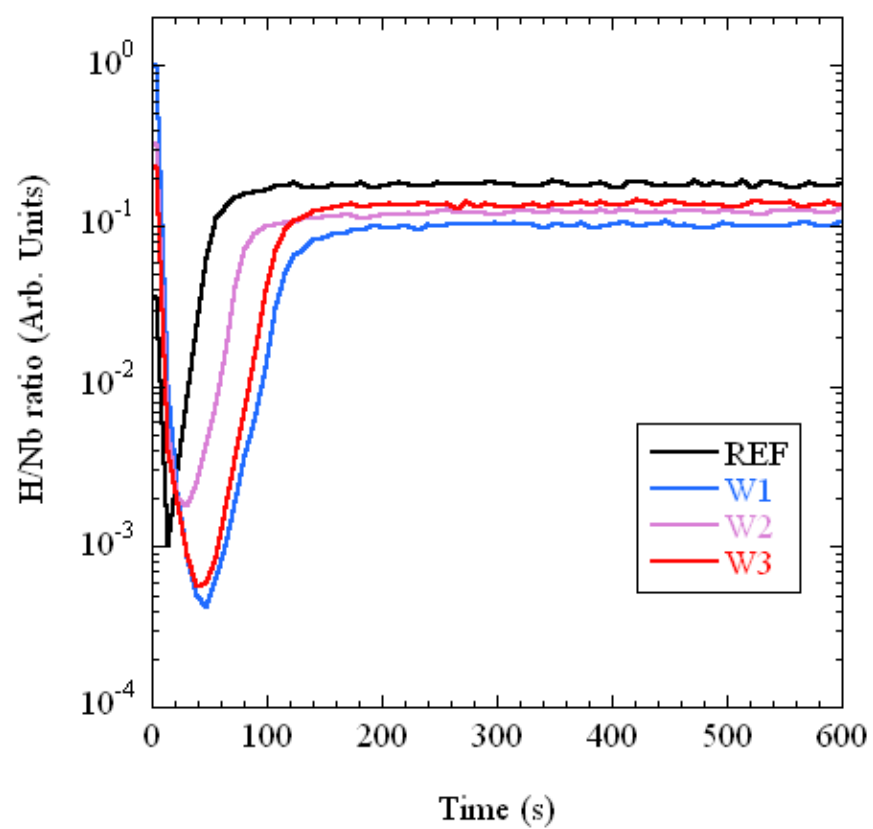

FIG. 13. (Color) SIMS Hydrogen depth profiling done at NCSU for samples baked at different temperatures. The sample treatments are indicated in Table I.

ing through the oxide is indicative of a loss of depth resolution. Depth resolution is degraded by the rough sample surface and by differential sputtering resulting from the differing sputter rates of the $\mathrm{Nb}$ crystallites of the polycrystalline $\mathrm{Nb}$ which are oriented at various angles to the SIMS primary ion beam. As a result, it is not possible to obtain oxygen diffusion information from the $\mathrm{O}^{-}$profiles. The samples roughness (rms values of $0.5-1 \mu \mathrm{m}$ ) was too high to measure the SIMS analysis craters with a profilometer and precluded a measurement of the oxide thickness using SIMS. Hydrogen is depleted in the oxide layer and was at about the same high level inside the $\mathrm{Nb}$ for all samples. The width of the hydrogen depletion region is well correlated to the oxide thickness measured by TEM. In order to obtain some idea of the hydrogen concentration, an hydrogen SIMS depth profile was made under the same conditions on a silicon sample implanted with $\mathrm{H}, \mathrm{C}$, and $\mathrm{O}$. The results showed that the hydrogen below the oxide in the $\mathrm{Nb}$ samples is approximately 2 orders of magnitude higher $\left(\sim 10^{5} \mathrm{cts} / \mathrm{s}\right)$ than the peak of hydrogen in $\mathrm{Si}$, which is known to be 0.4 at.\% and the hydrogen concentration did not significantly decrease over a $15 \mu \mathrm{m}$ depth. Similar high hydrogen concentrations were also measured with the same apparatus and with similar conditions on single-crystal $\mathrm{Nb}$ samples [13], even after they were degassed at $600^{\circ} \mathrm{C}$ for $10 \mathrm{~h}$.

One large-grain $\mathrm{Nb}$ sample has been baked in air at $120^{\circ} \mathrm{C}$ for $3 \mathrm{~h}$ with the single-cell cavity (the cavity test results are shown in Fig. 10). Oxygen depth profiling have been done with SIMS at Jefferson Lab, on the baked sample and on a large-grain sample from the same sheet

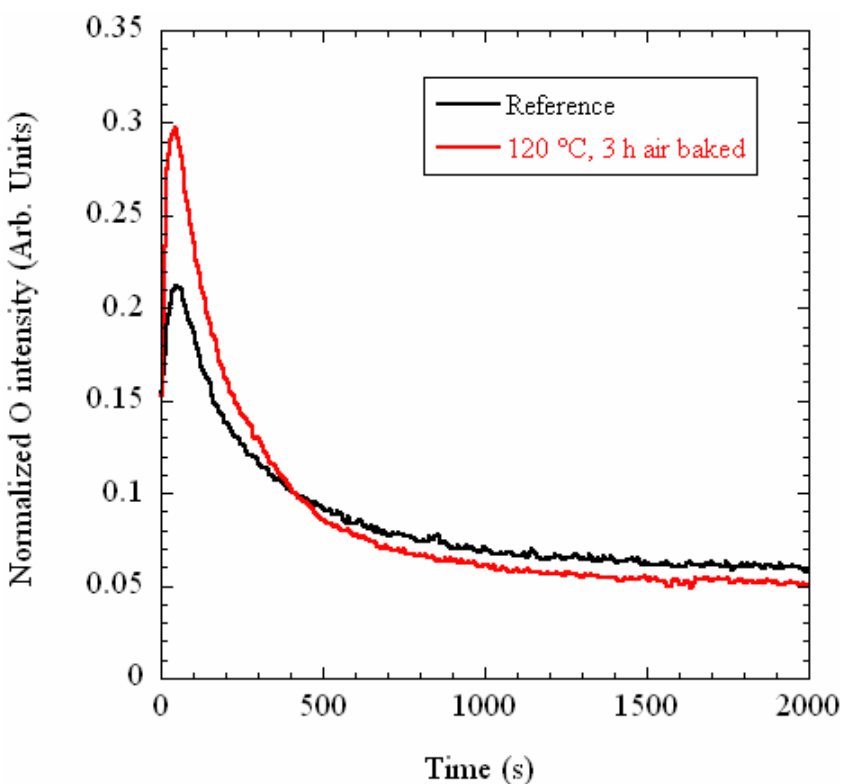

FIG. 14. (Color) SIMS depth profile of the total oxygen content normalized to the $\mathrm{Nb}$ peak done at Jefferson Lab for two largegrain samples, unbaked as reference and baked in air at $120^{\circ} \mathrm{C}$ for $3 \mathrm{~h}$.

which had not been baked. The results, displayed in Fig. 14, show an increased oxygen concentration at the surface after baking.

\section{HYDROGEN DEGASSING AND POSTPURIFICATION}

In order to investigate the cause for the increase in the number of hot spots introduced by the air baking at $180^{\circ} \mathrm{C}$ and which were not significantly reduced by additional chemical etching, we wanted to evaluate the influence of

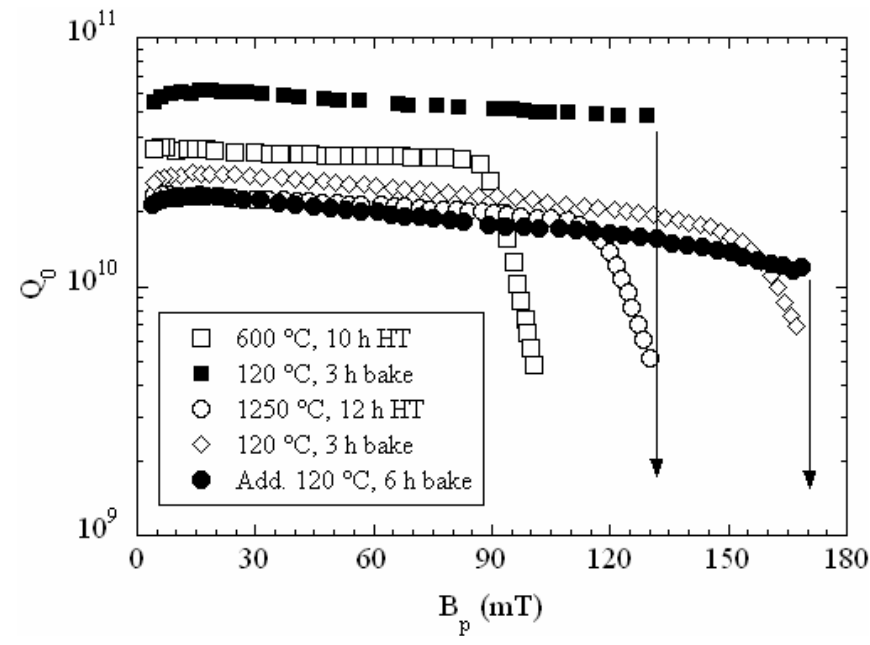

FIG. 15. $Q_{0}$ vs $B_{p}$ measured at $1.7 \mathrm{~K}$ after hydrogen degassing at $600^{\circ} \mathrm{C}$ and in situ baking and after postpurification at $1250^{\circ} \mathrm{C}$ and two consecutive in situ bakings. 
interstitial impurities by heat treating the cavity in a vacuum furnace in two steps: at $600^{\circ} \mathrm{C}$ first and at $1250^{\circ} \mathrm{C}$ with titanium second. The heat treatments at $600^{\circ} \mathrm{C}$ for $10 \mathrm{~h}$ or $800^{\circ} \mathrm{C}$ for $3 \mathrm{~h}$ remove interstitial hydrogen from niobium [23] and is commonly applied to niobium rf cavities to prevent $Q$-disease. For the second heat treatment, the cavity is placed in a titanium box and heated to $1250^{\circ} \mathrm{C}$. A titanium layer is evaporated on the cavity surface and acts as a getter for impurities such as oxygen, nitrogen, and hydrogen. In niobium the diffusion velocity of oxygen between $1100^{\circ} \mathrm{C}$ and $1300^{\circ} \mathrm{C}$ is of the order of millimeters per hour, approximately six to 7 times faster than for carbon and nitrogen. Therefore removal of oxygen is more likely in this temperature range [24]. Hydrogen gas released by niobium at high temperatures is absorbed readily by $\mathrm{Ti}$ between $25^{\circ} \mathrm{C}$ and $400^{\circ} \mathrm{C}$ [25]. The detailed postpurification procedure consisted of heating the cavity to $1250^{\circ} \mathrm{C}$ and maintaining the temperature constant for $12 \mathrm{~h}$. Then the temperature is reduced to $1000^{\circ} \mathrm{C}$ at a rate of $0.2^{\circ} \mathrm{C} / \mathrm{min}$ before the cooldown to $25^{\circ} \mathrm{C}$. The main
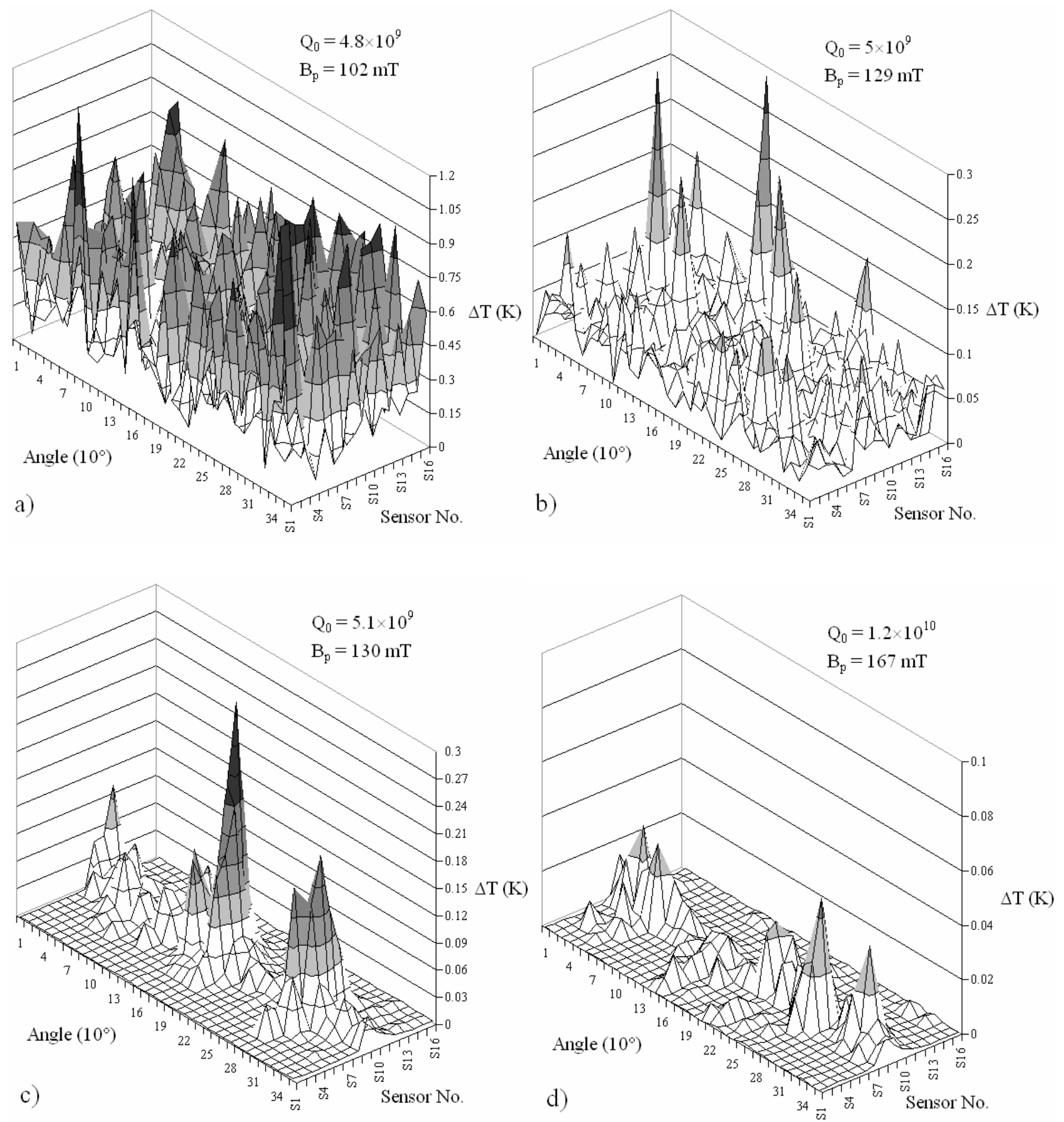

FIG. 16. Temperature maps at the He bath temperature of $1.7 \mathrm{~K}$ at the highest $\mathrm{rf}$ field achieved after hydrogen degassing at $600^{\circ} \mathrm{C}(\mathrm{a})$ followed by $120^{\circ} \mathrm{C}, 3 \mathrm{~h}$ in situ baking (b), and after postpurification with $\mathrm{Ti}$ at $1250^{\circ} \mathrm{C}$ (c), followed by $120^{\circ} \mathrm{C}, 3 \mathrm{~h}$ and $120^{\circ} \mathrm{C}, 6 \mathrm{~h}$ in situ baking (d). Note the different $\Delta T$ scales. 
residual gas in the furnace was hydrogen, with a maximum partial pressure of $\sim 7 \times 10^{-6}$ Torr at $1250^{\circ} \mathrm{C}$.

After the first heat treatment at $600^{\circ} \mathrm{C}$, the cavity was etched by BCP 1:1:2, removing $\sim 17 \mu \mathrm{m}$ of material. The rf tests at 1.7 and $2.0 \mathrm{~K}$ showed $Q$-drop starting at $B_{p} \cong$ $87 \mathrm{mT}$ with no field emission. The residual resistance was only $3 \mathrm{n} \Omega$. The temperature maps still showed extended rf losses over the whole cavity surface and high thermal response from the thermometers. In situ baking at $120^{\circ} \mathrm{C}$ for $3 \mathrm{~h}$ provided a significant reduction of the losses, $R^{0}{ }_{\text {res }}$ decreased to $1.6 \mathrm{n} \Omega$ and no $Q$-drop was found up to a quench field of $125 \mathrm{mT}$. The $Q_{0}$ vs $B_{p}$ curves at $1.7 \mathrm{~K}$ before and after baking are shown in Fig. 15. The temperature maps at the highest field before and after baking are shown in Figs. 16(a) and 16(b), respectively.

After the postpurification treatment, a $\sim 55 \mu \mathrm{m}$ thick layer was removed from the inner cavity surface by BCP 1:1:1. The baseline rf test showed $Q$-drop starting at $B_{p} \cong$ $115 \mathrm{mT}$ with no field emission. The $Q$-drop onset was raised to $146 \mathrm{mT}$ by in situ baking at $120^{\circ} \mathrm{C}$ for $3 \mathrm{~h}$ and the cavity quenched at $B_{p} \cong 165 \mathrm{mT}$. An additional in situ bake at $120^{\circ} \mathrm{C}$ for $6 \mathrm{~h}$ eliminated the $Q$-drop up to the quench field (165 mT, at location 30-9). As it can be seen from the temperature maps after postpurification shown in Fig. 16(c), it was only after this treatment that most of the cavity surface showed no distributed rf losses but only a few hot spots in the equator region, similar to the map showed in Fig. 3(b). In addition, it was only after postpurification that the value of the thermometers' thermal transfer coefficient, $K_{T}$, was reduced to $\sim 8 \mathrm{~K} \mathrm{~cm}^{2} / \mathrm{W}$, as before the air baking at high temperatures. Postpurification also restored the high quench field value which was obtained in the first tests, described in Sec. III. The $Q_{0}$ vs $B_{p}$ curves at $1.7 \mathrm{~K}$ before and after baking are shown in Fig. 15. The temperature maps at the highest field before and after the second baking are shown in Figs. 16(c) and 16(d), respectively.

\section{ANALYSIS OF EXPERIMENTAL DATA}

\section{A. Medium field $Q$-slope}

The quality factor of superconducting bulk niobium cavities has a mild degradation between $B_{p}=$ 20-90 mT, which is referred to as "medium field $Q$-slope." The following field dependence of the surface resistance, $R_{s}$, provided a good fit of a large set of experimental data on fine-grain, large-grain, and single-crystal niobium cavities [26]:

$$
R_{s}\left(T, B_{p}\right)=R_{\text {res }}^{1}(T)\left(\frac{B_{p}}{B_{c}}\right)+R_{s 0}(T)\left[1+\gamma^{*}(T)\left(\frac{B_{p}}{B_{c}}\right)^{2}\right] .
$$

Here $R_{s 0}, \gamma^{*}$, and $R_{\text {res }}^{1}$ are regarded as positive fitting parameters. $B_{c}=200 \mathrm{mT}$ is the thermodynamic critical field at $T=0$ of niobium and $T_{0}$ is the He bath tempera-
TABLE II. Weighted average values of $R_{s 0}, \gamma^{*}, R_{\text {res }}^{1}$, and average values of $r^{2}$ at 1.7 and $2.0 \mathrm{~K}$ for a standard $\mathrm{BCP}$ treatment and in situ baking at $120^{\circ} \mathrm{C}$ for $3-12 \mathrm{~h}$.

\begin{tabular}{lcc}
\hline \hline & BCP treatment & $120^{\circ} \mathrm{C}, 3-12 \mathrm{~h}$ in situ bake \\
\hline$T=1.7 \mathrm{~K}$ & & \\
$R_{s 0}(\mathrm{n} \Omega)$ & $10.4 \pm 0.1$ & $7.1 \pm 0.1$ \\
$R_{\text {res }}(\mathrm{n} \Omega)$ & $2.4 \pm 0.2$ & $2.8 \pm 0.2$ \\
$\gamma^{*}{ }^{2}$ & $0.42 \pm 0.03$ & $0.73 \pm 0.03$ \\
$r^{2}=2.0 \mathrm{~K}$ & 0.965 & 0.996 \\
$R_{s 0}(\mathrm{n} \Omega)$ & $24.2 \pm 0.1$ & \\
$R_{\text {res }}(\mathrm{n} \Omega)$ & $7.1 \pm 0.5$ & $17.7 \pm 0.1$ \\
$\gamma^{*}$ & $0.07 \pm 0.03$ & $15.0 \pm 0.8$ \\
$r^{2}$ & 0.929 & $0.06 \pm 0.06$ \\
\hline \hline
\end{tabular}

ture. The parameter $\gamma^{*}$ is determined by the thermal feedback provided by the BCS surface resistance and thermal impedance of the outer cavity surface [26] and by nonlinear pair breaking [27]. The coefficient $R^{1}{ }_{\text {res }}$ can be due to losses produced by Josephson fluxons penetrating grain boundaries [26] or by flux flow of Abrikosov vortices oscillating at the surface. The weighted average values of $R_{s 0}, \gamma^{*}, R_{\text {res }}^{1}$, and of the fit correlation factor $r^{2}$ from $R_{s} \mathrm{vs}$ $B_{p}$ fits at 1.7 and $2.0 \mathrm{~K}$ obtained for a standard $\mathrm{BCP}$ treatment and in situ baking at $120^{\circ} \mathrm{C}$ for $3-12 \mathrm{~h}$ are summarized in Table II. The results are consistent with the data of Ref. [26]: below $2 \mathrm{~K}$, the field dependence of the surface resistance is mostly quadratic while it is mostly linear at $2.0 \mathrm{~K}$. The coefficients $\gamma^{*}$ at $1.7 \mathrm{~K}$ and $R_{\text {res }}^{1}$ at $2.0 \mathrm{~K}$ increase by approximately a factor of 2 by baking while the low-field surface resistance, $R_{s 0}$ is reduced due to the lower $R_{\mathrm{BCS} 0}$. The $R_{s}\left(B_{p}\right)$ dependence after air baking at $180^{\circ} \mathrm{C}$ is quadratic with $\gamma^{*}$-values of 2.9 and 3.6 at 2.0 and $1.7 \mathrm{~K}$, indicating enhanced heating by reduced Kapitza conductance and high residual resistance.

\section{B. Relation between the energy gap value and the cavity performance}

The weighted average values of $R_{\text {res }}^{0}, \Delta / k T_{c}$, and $l$ obtained from the fits of the temperature dependence of the low-field surface resistance with Eq. (1) for data after BCP treatment and after in situ baking at $120^{\circ} \mathrm{C}$ for $12 \mathrm{~h}$ are indicated in Table III. In addition, the results from the tests described in Sec. II showed that anodization and baking are two surface treatments which alter the energy gap in opposite ways: anodization of a baked cavity surface at increasing voltages progressively reduces the gap, while baking at $120^{\circ} \mathrm{C}$ for longer times progressively increases it. The value of the energy gap for bulk $\mathrm{Nb}$ is approximately $1.6 \mathrm{meV}$ [20], corresponding to a ratio $\Delta / k T_{c}$ of 2.007 . $^{2}$ The value of $\Delta / k T_{c}$ obtained from the $R_{s}(T)$ fits is an

\footnotetext{
${ }^{2} \mathrm{~A}$ constant value of $T_{c}=9.25 \mathrm{~K}$ was assumed in the calculations of the BCS surface resistance used to fit the data.
} 
TABLE III. Weighted average values of $R^{0}{ }_{\text {res }}, \Delta / k T_{c}$ and $l$ obtained from fits of $R_{s}(T)$ data with Eq. (2) for a standard BCP treatment and in situ baking at $120^{\circ} \mathrm{C}$ for $12 \mathrm{~h}$.

\begin{tabular}{lcc}
\hline \hline & BCP treatment & $120^{\circ} \mathrm{C}, 12 \mathrm{~h}$ in situ bake \\
\hline$R_{\text {res }}^{0}(\mathrm{n} \Omega)$ & $4.8 \pm 0.2$ & $11.2 \pm 0.2$ \\
$\Delta / k T_{c}$ & $1.807 \pm 0.008$ & $1.919 \pm 0.004$ \\
$l(\mathrm{~nm})$ & $49 \pm 5$ & $16 \pm 50$ \\
\hline \hline
\end{tabular}

average over a depth of the order of few times the penetration depth ( $\sim 40 \mathrm{~nm}$ between 4.3 and $1.7 \mathrm{~K}$ ). The lower value of $\Delta / k T_{c}$ after BCP may suggest a space dependence (sketched in Fig. 17) characterized by a thin layer with depressed superconductivity near the surface, such as considered in the description of proximity effects [28], which baking is able to reduce.

The data also show a good correlation between $\Delta / k T_{c}$ and the values of $B_{p}$ corresponding to the onset of $Q$-drop and to a quench, for all the rf tests done on the single-cell cavity. This could be interpreted in a simple way, by considering the dependence of the breakdown magnetic field on the energy gap in the thermal feedback model [27]:

$$
H_{p}^{2}=\frac{C}{R_{s}}=C_{0} e^{\Delta / k T},
$$

where $C_{0}$ depends on thermal constants and on the gap. If we consider only the much stronger exponential dependence of $H_{p}$ on $\Delta$, ignoring a weaker power law dependence of $C_{0}$ on $\Delta$, we obtain that, from Eq. (5), a variation of the energy gap from a value $\Delta_{0}$ to $\Delta$ changes the breakdown field from $H_{p 0}$ to $H_{p}$ as follows:

$$
H_{p}=H_{p 0} e^{\left(\Delta-\Delta_{0}\right) /(2 k T)} \text {. }
$$

A fit of the $B_{p}$-values corresponding to the onset of $Q$-drop and quench as a function of $\Delta$ with Eq. (6), shown in Fig. 18, gave the following values of $H_{p 0}$ and $\Delta_{0}: H_{p 0}=$ $197 \mathrm{mT}, \Delta_{0}=2.051$, and fit correlation factor $r^{2}=0.77$. These results for $H_{p 0}$ and $\Delta_{0}$ are close to the measured values of the critical field of niobium at $2 \mathrm{~K}$ and the gap value for pure niobium, respectively. Equation (6) then

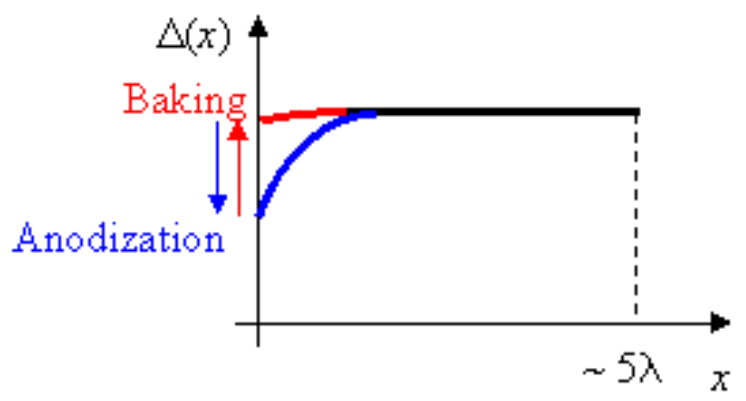

FIG. 17. (Color) Schematic representation of the space dependence of the energy gap and of the changes due to in situ baking and anodization. $x$ represents the depth from the surface.

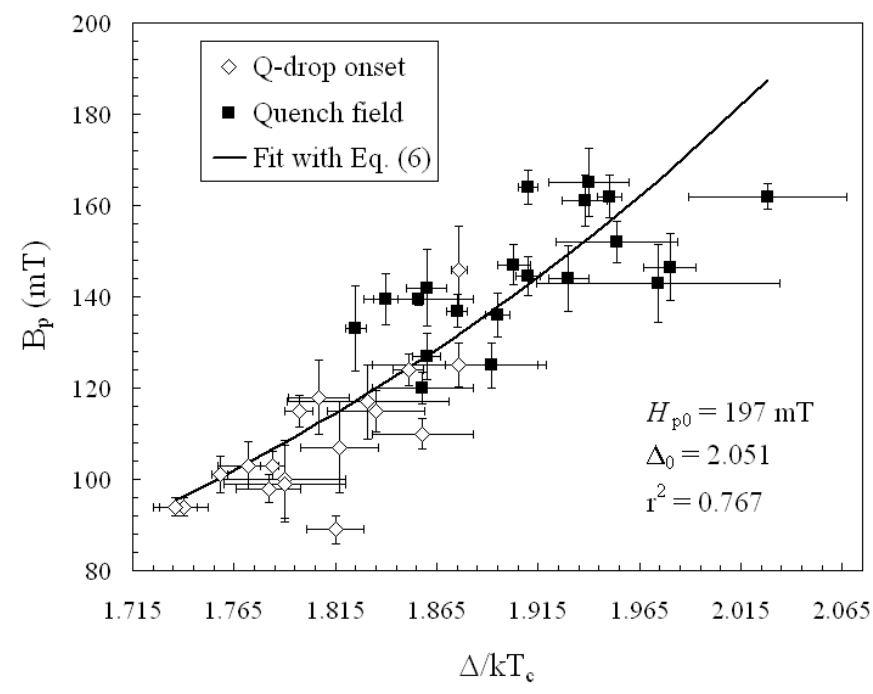

FIG. 18. $B_{p}$ values at $2 \mathrm{~K}$ corresponding to the onset of $Q$-drop or quench as a function of $\Delta / k T_{c}$ fitted with Eq. (6) with $H_{p 0}$ and $\Delta_{0}$ as fit parameters.

suggests that the reduced gap value obtained in a chemically polished niobium surface yields a reduced value of the critical field. Vortices will then enter in the niobium at this field, which is low enough to keep the cavity thermally stable, and cause a reduction of $Q_{0}$ ( $Q$-drop), for example, by flux flow losses. The gap value is raised by baking and so is the critical field and, in this case, vortices entering the niobium at higher field cause a thermal breakdown of the cavity.

\section{Field dependence and spatial distribution of hot-spot heating}

The field dependence of the heat generated at hot spots on the cavity surface, measured by thermal maps, can be analyzed by plotting $\log (\Delta T)$ vs $\log \left(B_{p}\right)$. Neglecting dielectric losses, the logarithmic slope, $n=\log (\Delta T) / \log$ $\left(B_{p}\right)$ is related to the field dependence of the surface resistance, where $n=2$ represents "ohmic-type" losses for which $R_{s}$ is independent of $B_{p}$. Since the hot spots usually occur in the equator region of the cavity where the local surface magnetic field is within $3 \%$ of $B_{p}$ for thermometers at locations 5 to 12 along the meridian, the $\Delta T$ from thermometers within this region was plotted as a function of $B_{p}$. Figure 19 shows the field dependence of $\log (\Delta T)$, which was typically observed at hot spots after a chemical etching and after in situ baking at $120^{\circ} \mathrm{C}$, along with a linear fit and the value of $n$. At the onset of $Q$-drop the dissipated power at hot-spot locations increases dramatically, as shown by the increase of $n$ by about 1 order of magnitude, and in situ baking at $120^{\circ} \mathrm{C}$ strongly reduces these anomalous losses. The $\Delta T\left(B_{p}\right)$ dependence for hot spots at fields lower than the onset of $Q$-drop does not differ significantly from the dependence measured on other locations of the cavity. In many cases the location of hot 


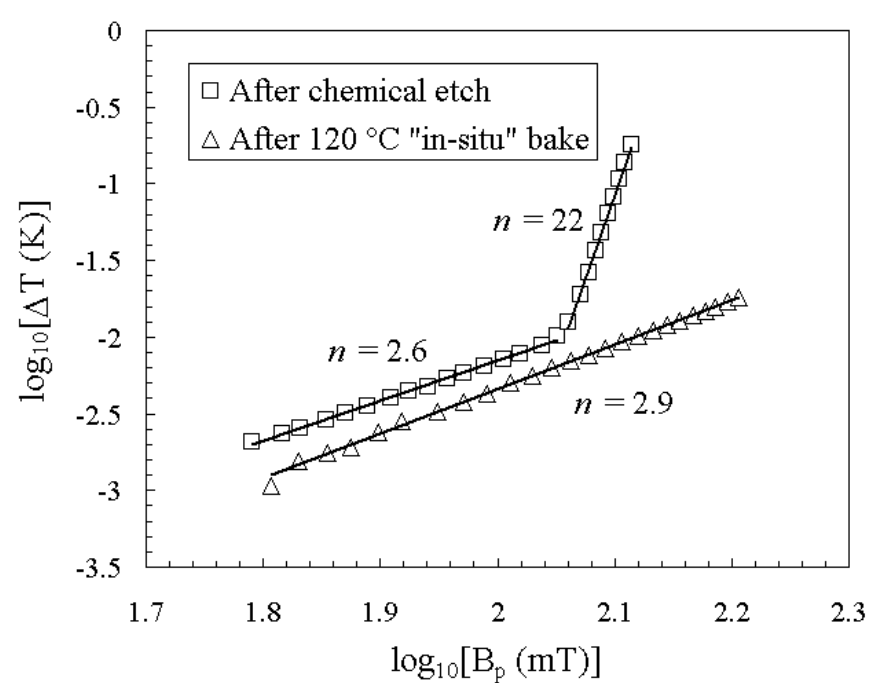

FIG. 19. $\log _{10}(\Delta T)$ vs $\log _{10}\left(B_{p}\right)$ typically measured for hot spots after a chemical etch of the cavity and after $120^{\circ} \mathrm{C}$ in situ baking. Solid lines represent linear fits with the indicated values of the slope, $n$.

spots causing the $Q$-drop did not correspond to the locations which showed higher losses at lower fields, due, for example, to higher local residual resistance.

An analysis of the effect of hot spots on the thermal balance of the cavity was presented in [27]. In the model, it is assumed that, besides the heat dissipated in the uniform part of the cavity, additional power is dissipated at a number of hot spots with reduced superconducting properties. From a solution of the heat balance equation, the following parametric dependence $Q_{0}\left(B_{p}\right)$ was obtained:

$$
\begin{aligned}
\frac{2 B_{p}^{2}}{B_{b 0}^{2}} & =1+g+u-\sqrt{(1+g+u)^{2}-4 u} \\
Q_{0} & =\frac{Q_{0}(0) e^{-\theta}}{1+g /\left[1-\left(B_{p} / B_{b 0}\right)^{2}\right]}
\end{aligned}
$$

where $\theta=\left(T_{m}-T_{0}\right) \Delta / k T_{0}^{2}, u=\theta e^{1-\theta}, g=\langle\eta\rangle \pi N_{h} L_{h}^{2}$, and $B_{b 0}$ is the breakdown field of the uniform portion of the cavity. $T_{m}$ and $T_{0}$ are the temperatures of the rf surface and of the He bath, respectively, $\langle\eta\rangle$ is the average of the parameter $\eta$ which quantifies the extra power generated by a hot spot, $N_{h}$ is the number of hot spots per unit area, and $L_{h}$ is the lateral thermal diffusion length. Equation (7) provides a very good fit of the experimental $Q_{0}$ vs $B_{p}$ curves at 2.0 and $1.7 \mathrm{~K}$ both before and after baking, as shown in Fig. 20, and the main effect of baking is the increase of the breakdown field $B_{b 0}$. The values of the fit parameters $Q_{0}(0), g, B_{b 0}$, and of the fit correlation factor $r^{2}$ for rf tests characterized by $Q$-drop are indicated in Table IV.

The fact that the parameter $g$ obtained from the fits is almost the same for 1.7 and $2 \mathrm{~K}$ is consistent with the

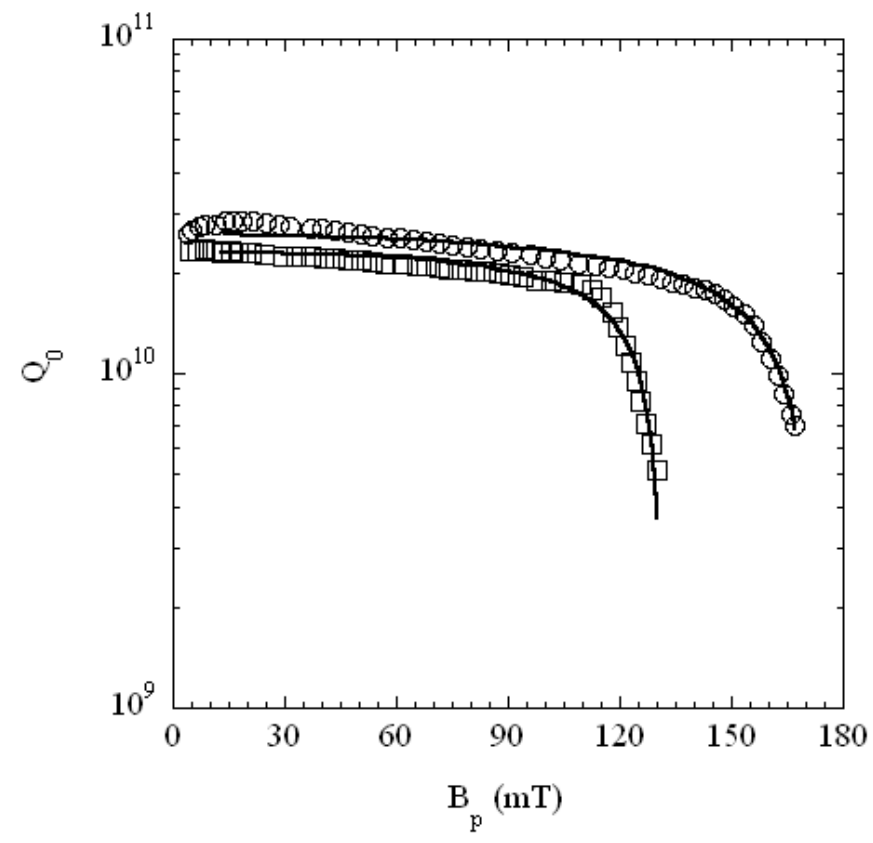

FIG. 20. $Q_{0}$ vs $B_{p}$ data measured after postpurification (squares) and after $120^{\circ} \mathrm{C}, 3 \mathrm{~h}$ in situ baking fitted with Eq. (7) (solid lines). The data were also shown in Fig. 15.

model [27] in which $g$ is mostly determined by the spatial distribution of the hot spots. It has been shown in [29] that the spatial distribution of hot-spots heating during the $Q$-drop is not compatible with the hypothesis of a hot spot being a small normal-conducting defect. Figure 21 shows the $\Delta T$-distribution along the meridian for thermometers neighboring a hot spot, normalized to the temperature at the hot-spot location, for increasing values of $\mathrm{rf}$ field in the $Q$-drop regime. The data show an expansion of the area affected by hot-spot heating for increasing of field and no significant difference was found between the distribution at 2.0 and $1.7 \mathrm{~K}$. This behavior was predicted by the same model [27].

\section{Grain boundary heating}

In order to investigate the role of grain boundaries on the $Q$-drop, we recorded after each rf test the location of hot spots with respect to grain boundaries, which are visible by eye in large-grain cavities. The temperature mapping system was always assembled with the same orientation and a fraction of 196/576 thermometers was near (within $1 \mathrm{~cm}^{2}$ around a thermometer) or on a grain boundary. We present the statistics on the hot-spots location for a total of $33 \mathrm{rf}$ tests. Hot spots occurred at 238 different locations and a fraction $89 / 238(37 \%)$ was near or on a grain boundary. The highest number of times that a hot spot occurred at the same location was seven. There were nine locations where the incidence of hot spots was greater or equal than five. A fraction 5/9 (56\%) of these locations were near or on a grain boundary. If we limit the statistic to hot spots which correlate with $Q$-drop $\left(n>4\right.$ for $\left.B_{p}>90 \mathrm{mT}\right)$, they were 
TABLE IV. Fit parameters $Q_{0}(0), g, B_{b 0}$ of Eq. (7) and fit correlation factor $r^{2}$ for rf tests limited by $Q$-drop at 2.0 and $1.7 \mathrm{~K}$.

\begin{tabular}{|c|c|c|c|c|c|c|c|c|}
\hline \multirow[b]{2}{*}{ Surface treatment } & \multicolumn{4}{|c|}{$1.7 \mathrm{~K}$} & \multicolumn{4}{|c|}{$2.0 \mathrm{~K}$} \\
\hline & $\begin{array}{c}Q_{0}(0) \\
\left(\times 10^{10}\right)\end{array}$ & $g$ & $\begin{array}{c}B_{b 0} \\
(\mathrm{mT})\end{array}$ & $r^{2}$ & $\begin{array}{c}Q_{0}(0) \\
\left(\times 10^{10}\right)\end{array}$ & $g$ & $\begin{array}{c}B_{b 0} \\
(\mathrm{mT})\end{array}$ & $r^{2}$ \\
\hline $54 \mathrm{~V}$ anodization & 1.3 & 0.20 & 111 & 0.985 & 0.8 & 0.20 & 116 & 0.943 \\
\hline $30 \mu \mathrm{m} \mathrm{BCP}$ & 2.0 & 0.22 & 117 & 0.981 & 1.1 & 0.22 & 122 & 0.960 \\
\hline $17 \mu \mathrm{m} \mathrm{BCP}$ & 3.2 & 0.15 & 112 & 0.966 & 1.4 & 0.15 & 117 & 0.939 \\
\hline $120^{\circ} \mathrm{C}, 5 \mathrm{~min}$ & 4.6 & 0.84 & 145 & 0.956 & 2.2 & 0.83 & 147 & 0.929 \\
\hline $600^{\circ} \mathrm{C}, 10 \mathrm{~h}$ & 4.2 & 0.18 & 101 & 0.955 & 1.5 & 0.10 & 102 & 0.936 \\
\hline $1250^{\circ} \mathrm{C}, 12 \mathrm{~h}$ & 2.7 & 0.17 & 132 & 0.983 & 1.3 & 0.12 & 133 & 0.958 \\
\hline $120^{\circ} \mathrm{C}, 3 \mathrm{~h}$ & 3.2 & 0.23 & 173 & 0.965 & 1.7 & 0.23 & 175 & 0.910 \\
\hline
\end{tabular}

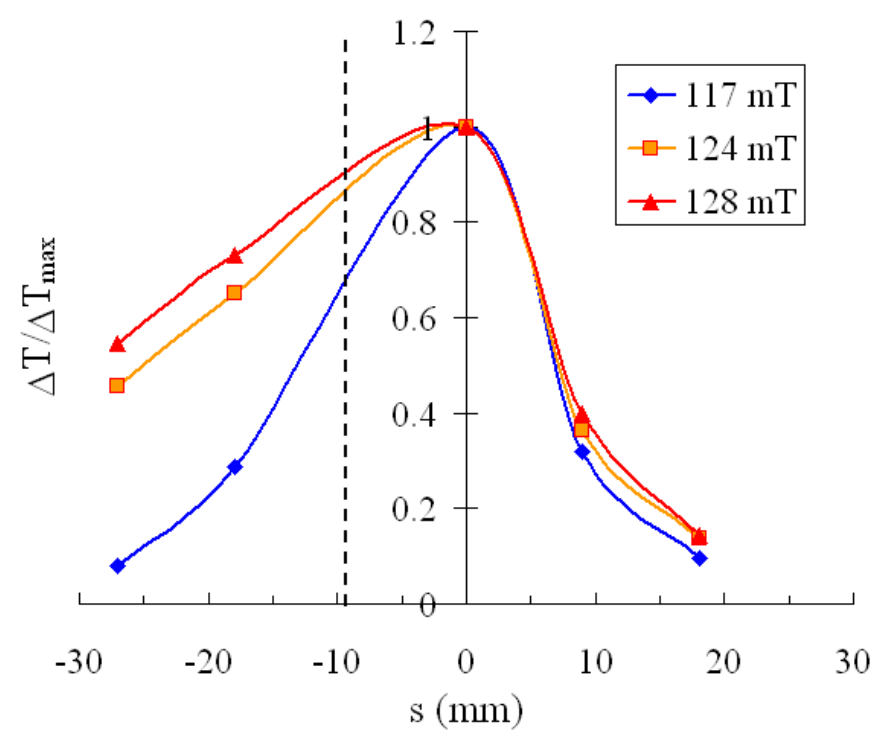

FIG. 21. (Color) Normalized $\Delta T$ spatial distribution for a hot spot at $s=0$ for increasing values of $B_{p}$ at $2.0 \mathrm{~K}$. The dashed line represents the location of the equator weld. found at 171 different locations and a fraction 52/171 $(30 \%)$ was near or on a grain boundary. The highest number of times that these hot spots occurred at the same location was five. There were eight locations where the incidence of hot spots was greater or equal than four. A fraction $4 / 8(50 \%)$ of these locations were near or on a grain boundary. In conclusion, grain boundaries do not seem to be the main source of hot spots, in agreement with a recent study on cavities with different grain size [30].

In the rf tests after postpurification it was found that the position of hot spots changes even after in situ baking at $120^{\circ} \mathrm{C}$ for $3 \mathrm{~h}$. We wanted to verify whether this could be associated with the diffusion of some impurity sideways, along a grain boundary, rather than in depth, but the patterns of three major hot spots in Fig. 16(c) did not show clear evidence for it. Figure 22 shows, for example, a temperature map limited to few thermometers surrounding a hot spot with the grain boundaries pattern superimposed for the rf tests after postpurification and after in situ baking at $120^{\circ} \mathrm{C}$ for $3 \mathrm{~h}$ and $6 \mathrm{~h}$.

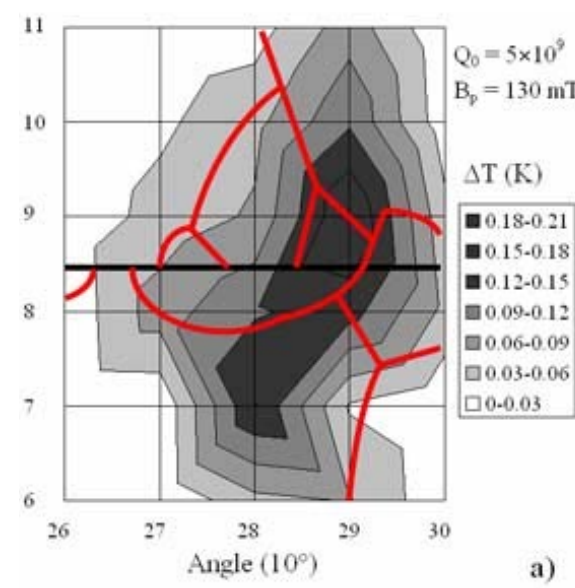

a)

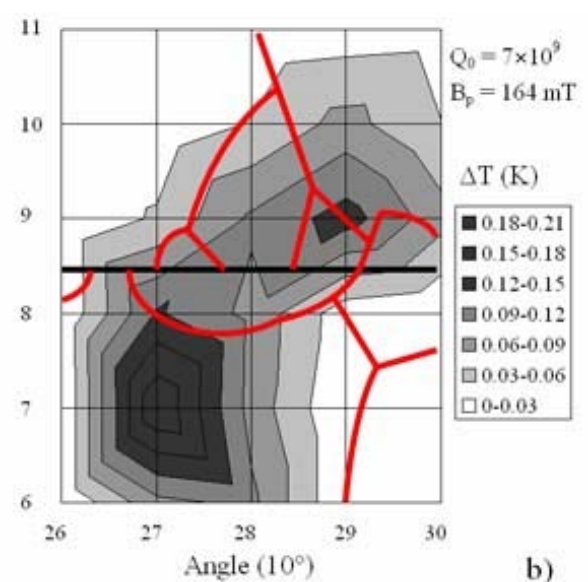

b)

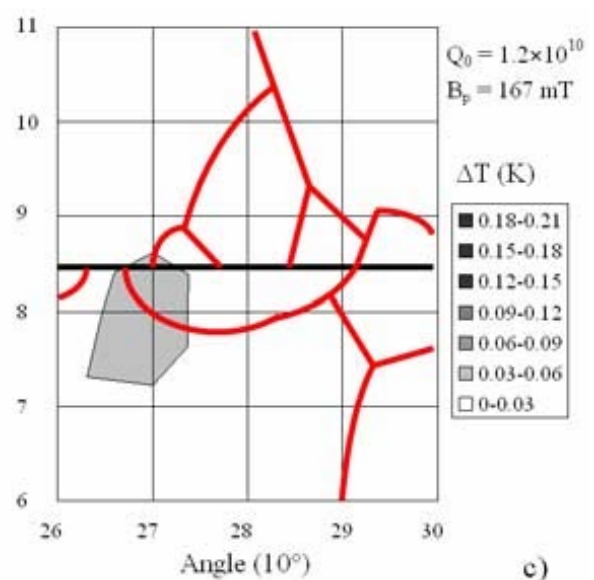

c)

FIG. 22. (Color) Temperature map for few thermometers surrounding a hot spot measured in the test after postpurification (a), after $120^{\circ} \mathrm{C}, 3 \mathrm{~h}$ in situ bake (b), and after additional $120^{\circ} \mathrm{C}, 6 \mathrm{~h}$ in situ bake (c). The thick red lines represent grain boundaries and the thick black line represents the equator weld. 


\section{E. Heating after $180^{\circ} \mathrm{C}$ air bake}

Baking at $180^{\circ} \mathrm{C}$ for $12 \mathrm{~h}$ in air caused uniformly distributed "anomalous" losses and the overall surface resistance of the cavity exhibited a strong quadratic dependence from the rf field, with coefficient $\gamma^{*}$ at $1.7 \mathrm{~K}$ approximately a factor of 5 higher than after standard in situ baking. In addition, the thermal response of the thermometers increased by about a factor of 10 and the outer cavity surface looked dark gray. All these may suggest an increase of the Kapitza resistance. On the other hand, baking of a cavity at $180^{\circ} \mathrm{C}$ for $48 \mathrm{~h}$ in UHV conditions did not cause the strong $R_{s}\left(B_{p}\right)$ dependence observed in this study [4]. This may suggest that the air baking introduced a large quantity of interstitial oxygen, as shown by SIMS, which may precipitate in metallic, normal conducting $\mathrm{NbO}_{x}(x \sim$ 1) suboxides, causing high, uniformly distributed rf losses, as shown by the temperature maps. These enhanced rf losses, combined with a higher Kapitza resistance, cause a warm-up of the cavity rf surface by thermal feedback, causing the quadratic $R_{s}\left(B_{p}\right)$ dependence obtained from the rf measurement. Another unusual result from the hightemperature air bake was the presence of high losses in the iris region of the cavity and could be explained by enhanced dielectric losses. Evidence for dielectric losses was previously reported in [31]. Figure 23 shows, for example, the $\Delta T$ distribution at low field $\left(B_{p}=16 \mathrm{mT}\right)$ along a meridian, from the cavity equator to the iris. The data could be fitted with Eq. (2) with $R_{s}$ decreasing from $10 \mathrm{n} \Omega$ at the equator to $3 \mathrm{n} \Omega$ at the iris and $R_{s}^{E}=$ $15 \mathrm{n} \Omega$. The dielectric surface resistance is given by [32]:

$$
R_{s}^{E}=\omega \mu_{0} d \varepsilon_{r} \tan \delta_{E}
$$

For an oxide thickness, $d$, of $10 \mathrm{~nm}$, and a relative dielec-

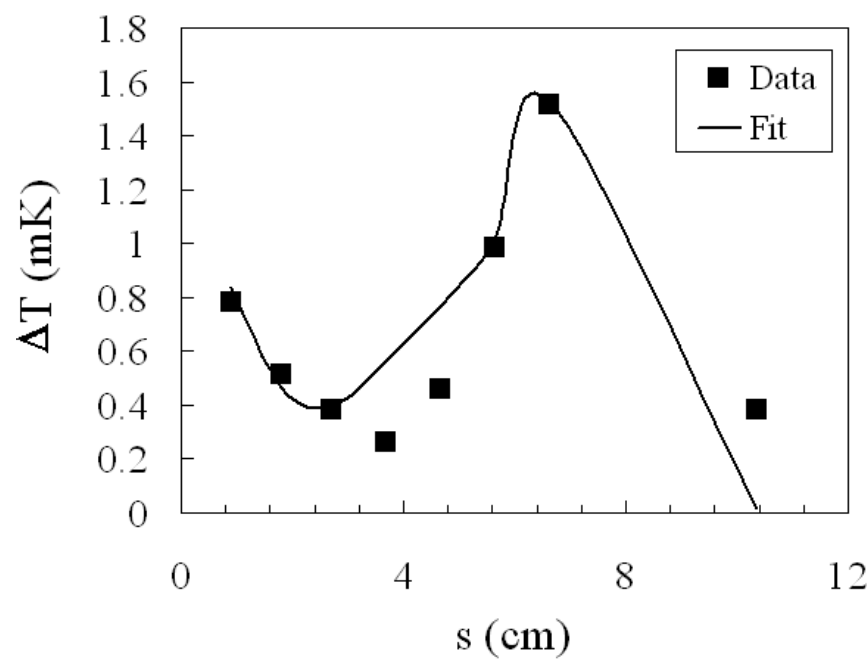

FIG. 23. $\Delta T$ distribution measured at $1.7 \mathrm{~K}$ and $B_{p}=16 \mathrm{mT}$ along a cavity meridian from the equator $(s=0 \mathrm{~cm})$ to the iris $(s=8.2 \mathrm{~cm})$ fitted using Eq. (2) with $K_{T}=10 \mathrm{~cm}^{2} \mathrm{~K} / \mathrm{W}, R_{s}=$ 3-10 $\mathrm{n} \Omega$ and $R_{s}^{E}=15 \mathrm{n} \Omega$. tric constant, $\varepsilon_{r}$, of $30, R_{s}^{E}=15 \mathrm{n} \Omega$ yields $\tan \delta_{E}=2.6 \times$ $10^{-5}$, well within the range of measured values [20]. In the hot-spot areas at the iris, $R_{s}^{E}$ is approximately a factor of 10 higher than in other regions of the cavity, which could be due to an increased relative dielectric constant or loss tangent due to higher defect density in the oxide.

\section{DISCUSSION}

The results from the anodization experiments confirm that the changes produced by the low-temperature in situ baking occur within about $30 \mathrm{~nm}$ deep into the niobium (corresponding to the $\sim 80 \mathrm{~nm}$ thick anodic $\mathrm{Nb}_{2} \mathrm{O}_{5}$ ). These results, combined with the fact that the baking effect is stable after exposure of the cavity to air for many months and to successive high-pressure water rinsing, exclude the possibility of the $Q$-drop being caused by adsorbates on the surface.

The increase of residual resistance observed after in situ baking, anodization, and electron impact on the oxide could be related in all cases to interface losses, described in Ref. [32], due to oxygen injection and $\mathrm{NbO}_{x}(x \sim 1)$ precipitates formed at the metal/oxide interface. The results presented in this contribution show that these residual losses are strongly reduced by forming a fresh oxide layer, and therefore a new interface, by HF rinse. However, the $Q$-drop does not reoccur in a baked cavity after HF rinse. This result, combined with measurements on $\mathrm{TE}_{011} / \mathrm{TM}_{010}$ modes in [33] and temperature maps showing hot spots in the high magnetic field region of the cavity, is in contrast with the so-called "interface tunnel exchange" model, which describes the $Q$-drop as being driven by the electric field causing a resonant tunneling of normal electrons between conduction states in the metal and localized states in the oxide.

The oxygen diffusion model is consistent with the experimental results related to the reduction of mean-free path, increase of $Q$-drop onset for longer baking time, and depth affected by baking. Nevertheless, no evidence for oxygen diffusion was found by SIMS on postpurified polycrystalline $\mathrm{Nb}$ samples in situ baked at $145^{\circ} \mathrm{C}$ for $3 \mathrm{~h}$ and $110^{\circ} \mathrm{C}$ for $60 \mathrm{~h}$, reported in [34]. In addition, the experiments presented in this article aimed at restoring the $Q$-drop by oxygen injection in a baked cavity first by a small amount, as obtained by the $120^{\circ} \mathrm{C}$ bake in oxygen atmosphere, then by larger amounts, as obtained by air baking at higher temperatures, were not successful. As a matter of fact, the $Q$-drop was significantly reduced up to $140 \mathrm{mT}$ by baking the cavity in air at $120^{\circ} \mathrm{C}$ for $3 \mathrm{~h}$, even though SIMS results show that the oxygen concentration near the surface is higher in the baked sample than in the one which was chemically etched only. Still, a too high oxygen concentration near the surface, as obtained by baking the wet cavity in air at $180^{\circ} \mathrm{C}$, is detrimental for the cavity performance and results in high interface and 
dielectric losses. At baking temperatures above about $150^{\circ} \mathrm{C}$, a reduction of the pentoxide into metallic suboxides was observed by $\mathrm{x}$-ray photoelectron spectroscopy [35], which may also introduce additional rf losses. The fact that some of these lossy areas could not be recovered by subsequent chemical etching, as shown by temperature maps, could be due to structural changes at the metal/oxide interface by high-temperature air baking, which favored the nucleation of hot spots with $Q$-drop behavior. These nuclei were dissolved by postpurification at $1250^{\circ} \mathrm{C}$.

Besides oxygen, the other impurity which is known to cause negative effects on the superconducting properties of niobium is hydrogen, which was studied intensively in the 1990 s in relation to the $Q$-disease issue. The hydrogen concentration in high-purity niobium is normally specified to be less than 10 wppm (0.092 at.\%). Hydrogen pickup by niobium occurs during chemical etching, wire electrodischarge machining or any other process which removes the protective oxide barrier in the presence of hydrogen rich media. Concentrations above $5 \mathrm{wppm}$ are high enough to cause precipitation of a metallic niobium hydride phase near the surface, in the temperature range between $70-$ $150 \mathrm{~K}$, which reduces the $Q_{0}$ of niobium cavities. This interstitial hydrogen is reduced by degassing in vacuum at $600-800^{\circ} \mathrm{C}$ for several hours. It was also found that hydrogen segregates towards the surface [36] and there can be trapped by interstitial impurities and defects, explaining why the $Q$-disease did not occur in low-RRR Nb cavities. It is likely that some hydrogen diffused into niobium during baking of the wet cavity in air at $180^{\circ} \mathrm{C}$, since at this temperature some decomposition of the $\mathrm{Nb}_{2} \mathrm{O}_{5}$ barrier occurs. The $Q$-disease tests which were done after the baking and additional chemical etching were negative, but this could be explained by the presence of interstitial oxygen and interface defects which trapped hydrogen (reactor-grade-like $\mathrm{Nb}$ at the surface). The SIMS results for all samples baked at various temperatures show very high hydrogen concentration ( $\sim 40$ at. \%) up to tens of micron deep into niobium. The most probable explanation could be charging during the heavy chemical etch of the samples.

In considering the possible role of hydrogen on $Q$-drop and in situ baking, high-RRR cavities which are limited by $Q$-drop do not normally show $Q$-disease, so we should assume that the total amount of hydrogen involved is less than in cavities affected by $Q$-disease. Measurements by nuclear reaction analysis reported in [4] showed some reduction of the hydrogen concentration near the surface by in situ baking. If hydrogen segregated near the surface is involved, the hydrogen degassing at $600^{\circ} \mathrm{C}-800^{\circ} \mathrm{C}$ alone does not eliminate the $Q$-drop, because the heat treatment is followed by a chemical etching where some hydrogen pickup always occurs. In situ baking for longer times would allow further reduction of the surface hydrogen concentration, therefore increasing the onset of $Q$-drop.
One important experimental evidence emerging from this study is the correlation between the energy gap of niobium and the onset of $Q$-drop and quench field. It was shown in Sec. 2 that this relation suggests that the $Q$-drop onset and quench field after baking are given by the combination of the change of the critical field and of the thermal stability of the cavity, with the energy gap acting as main parameter. The lower value of the energy gap obtained by chemical treatment of niobium has been attributed in the past to interstitial oxygen and normalconducting $\mathrm{NbO}_{x}$ precipitates at the metal/oxide interface, formed during the "wet" oxidation of niobium [20]. Those conclusions were inferred mainly from measurements of superconducting properties (penetration depth) of lowRRR niobium samples. To the authors' knowledge, there exist no clear evidence for such features by surface analytical techniques. In this study, the resolution of the TEM images is not sufficient to draw definitive conclusions on this aspect. The gap reduction after chemical treatment and anodization does not favor the involvement of hydrogen, since positive (anodic) polarization of the cavity reduces the hydrogen pickup and changes of the energy gap due to hydrogen were observed only at high enough concentrations to cause $Q$-disease [37].

Regarding the location of the hot spots, the grain boundaries provide some, although not dominant, contribution. It was shown in Ref. [38] that the losses due to vortex penetration along strongly coupled low-angle grain boundaries can be almost as low as losses in the bulk. This may explain why some grain boundaries show higher rf losses than others, and many hot spots observed on our thermals maps are not associated with grain boundaries at all.

\section{CONCLUSIONS}

The anodization and HF rinse tests reported in this article confirm previous results on small-grain polycrystalline cavities, for large-grain niobium cavities: in situ baking affects the properties of niobium up to a depth of $20-$ $30 \mathrm{~nm}$ and the growth of a new oxide layer on a baked cavity, after HF rinse, does not restore the $Q$-drop. The baked cavity was resistant against the occurrence of $Q$-drop even after oxygen injection by additional bakeouts in a pure oxygen atmosphere and in air, at higher temperatures. Sufficiently high oxygen concentrations, as achieved by baking in air at $180^{\circ} \mathrm{C}$ for $12 \mathrm{~h}$, introduced higher dielectric and interface losses and reduced the thermal transfer efficiency between niobium and the He bath. Temperature maps showed that the only treatment which allowed a complete recovery from these losses was postpurification with $\mathrm{Ti}$ at $1250^{\circ} \mathrm{C}$. If the baking temperature is sufficiently low $\left(\leq 120^{\circ} \mathrm{C}\right)$, the oxide dissociation and oxygen injection from the surrounding atmosphere are minimal and a significant improvement of the $Q$-drop can be achieved by baking in air. 
The onset of $Q$-drop in the large-grain cavity is raised up to $B_{p}=145 \mathrm{mT}$ by in situ baking at $120^{\circ} \mathrm{C}$ for $3 \mathrm{~h}$ and above $B_{p}=165 \mathrm{mT}$ after a total of $9 \mathrm{~h}$, which is shorter than the typical $48 \mathrm{~h}$ baking required on fine-grain cavities. This would help in reducing the cavity preparation times, which is an important aspect for large-scale cavity production projects. A quench field of about $145 \mathrm{mT}$ was routinely achieved in this cavity and the highest $B_{p}$-value of $165 \mathrm{mT}$, obtained with postpurification at $1250^{\circ} \mathrm{C}$, corresponds to an accelerating gradient $E_{\text {acc }}=38.7 \mathrm{MV} / \mathrm{m}$ in a ILCTESLA shaped cavity and to $E_{\text {acc }}=46 \mathrm{MV} / \mathrm{m}$ in a ILCLL shape [39], well above the value of $31.5 \mathrm{MV} / \mathrm{m}$ required for the ILC project and comparable to the best finegrain cavities treated by electropolishing.

A correlation between the onset of $Q$-drop, the quench field, and the energy gap emerges from the data, supporting the hypothesis of thermomagnetic breakdown. The field and space dependence of the heat generated at hot spots causing the $Q$-drop fit this description well. As for the physical origin of this phenomenon, oxygen diffusion does not seem to play a major role. Hydrogen may be involved, although more systematic studies are necessary. The investigation of hydrogen in niobium by conventional surface analytical techniques is made difficult by its high mobility in $\mathrm{Nb}$ and by being present as the main residual gas in the analysis chambers. A well-trusted, reliable characterization method and procedure with high enough sensitivity is necessary for clear results. More detailed studies of the oxide/metal interface are also desirable to clearly identify the presence of suboxide clusters and modifications introduced by baking. The investigation of grain boundaries in niobium, their resistance, depairing current density, and dependence from the misorientation angle would be helpful in the understanding of loss mechanisms due to vortices of various kinds.

\section{ACKNOWLEDGMENTS}

We would like to thank G. Myneni, J. Halbritter, J. Delayen, and H. Tian for many interesting discussions, A. Wu for SIMS measurements at Jefferson Lab, F. Stevie and D. Batchelor for SIMS and TEM analysis at NCSU. We would like also to acknowledge E. Daly for helping with the safety procedure for the oxygen bake, M. Morrone for the assembly of the temperature mapping system, D. Forehand for the hydrogen degassing and postpurification of the cavity, and P. Kushnick for cryogenic support. This manuscript has been authored by Jefferson Science Associates, LLC under U.S. DOE Contract No. DE-AC0506OR23177. The U.S. Government retains a nonexclusive, paid-up, irrevocable, world-wide license to publish or reproduce this manuscript for U.S. Government purposes.

[1] F. Furuta, K. Saito, T. Saeki, H. Inoue, Y. Morozumi, T. Higo, Y. Higashi, H. Matsumoto, S. Kazakov,
H. Yamaoka, K. Ueno, Y. Kobayashi, R.S. Orr, and J. Sekutowicz, in Proceedings of the 2006 European Particle Accelerator Conference, Edinburgh, Scotland, 2006, edited by C. Biscari, H. Owen, Ch. Petit-JeanGenaz, J. Poole, J. Thomason, paper MOPLS084.

[2] B. Visentin, in Proceedings of the 11th Workshop on RF Superconductivity, Travemünde, 2003, edited by D. Proch (DESY, Hamburg, Germany, 2004); and G. Ciovati, Physica C (Amsterdam) 441 , 44 (2006).

[3] Available from http://www.interactions.org/linearcollider

[4] G. Ciovati, J. Appl. Phys. 96, 1591 (2004).

[5] B. Visentin, J.P. Charrier, and G. Congretel, in Proceedings of the 2001 Particle Accelerator Conference, Chicago, 2001, edited by P.W. Lucas and S. Webber (FNAL, Batavia, IL, 2001) p. 1056.

[6] G. Ciovati, Appl. Phys. Lett. 89, 022507 (2006).

[7] P. Kneisel, G. Ciovati, G. R. Myneni, T. Carneiro, and J. Sekutowicz, in Proceedings of the 2005 Particle Accelerator Conference, Knoxville, 2005, edited by C. Horak (ORNL, Oak Ridge, TN, 2005), p. 3991.

[8] R. M. Sundelin, IEEE Trans. Nucl. Sci. 32, 3570 (1985).

[9] J.H. Billen and L.M. Young, Los Alamos National Laboratory, LA-UR-96-1834, 2004.

[10] G. Ciovati, Jefferson Lab, JLAB-TN-05-059, 2005.

[11] G. Ciovati, Jefferson Lab, JLAB-TN-03-003, 2003.

[12] J. Halbritter, Forschungszentrum Karlsruhe, FZK 3/70-6, 1970.

[13] A. D. Batchelor, D. N. Leonard, P. E. Russell, F. A. Stevie, D. P. Griffis, and G. R. Myneni, in Proceedings of the Single Crystal Niobium Technology Workshop, Araxa, Brasil, 2006 (to be published).

[14] A. T. Wu, in Proceedings of the 11th Workshop on RF Superconductivity, Travemünde, Germany, 2003, edited by D. Proch (DESY, Hamburg, Germany, 2004).

[15] F. Stevie (private communication).

[16] H. Pfister, Cryogenics 16, 17 (1976).

[17] L. Young, Anodic Oxide Films (Academic Press, New York, 1961).

[18] G. Eremeev and H. Padamsee, Physica C (Amsterdam) 441, 62 (2006).

[19] H. J. Halama, Appl. Phys. Lett. 19, 90 (1971).

[20] J. Halbritter, Appl. Phys. A 43, 1 (1987).

[21] B. Visentin, in Proceedings of the Pushing the Limits of RF Superconductivity Workshop, Argonne, 2004, edited by K.-J. Kim and C. Eyberger (ANL, Argonne, IL, 2005), p. 94.

[22] B. Bonin and R.W. Röth, in Proceedings of the 5th Workshop on RF Superconductivity, Hamburg, Germany, 1991, edited by D. Proch (DESY, Hamburg, Germany, 1991), p. 210; J. Knobloch, in Proceedings of the 1st International Workshop on Hydrogen in Materials \& Vacuum Systems, Newport News, Virginia, 2002, edited by G. R. Myneni and S. Chattopadhyay, AIP Conf. Proc. No. 671 (AIP, Melville, New York, 2003), p. 133.

[23] D. Moffat and D. Proch, Cornell Report CNLS 90/IC35; R.L. Paul, H.H. Chen-Mayer, and G. Myneni, in Proceedings of the 1st International Workshop on Hydrogen in Materials \& Vacuum Systems, Newport News, Virginia, 2002, edited by G. R. Myneni and S. Chattopadhyay, AIP Conf. Proc. No. 671 (AIP, Melville, New York, 2003), p. 151. 
[24] P. Kneisel, J. Less-Common Met. 139, 179 (1988).

[25] V.L. Stout and M.D. Gibbons, J. Appl. Phys. 26, 1488 (1955).

[26] G. Ciovati and J. Halbritter, Physica C (Amsterdam) 441, 57 (2006).

[27] A. Gurevich, Physica C (Amsterdam) 441, 38 (2006).

[28] P. G. de Gennes, Superconductivity of Metals and Alloys (Benjamin, New York, 1966).

[29] G. Ciovati, Ph.D. thesis, Old Dominion University, 2005.

[30] P. Kneisel, G. Ciovati, S. Chattopadhyay, and G. R. Myneni, in Proceedings of the 2006 Linear Accelerator Conference, Knoxville, TN, 2006, edited by N. Holtkamp (ORNL/SNS, Oak Ridge, TN, 2006), p. 318.

[31] R. W. Röth, V. G. Kurakin, G. Müller, H. Piel, J. Pouryamout, D. Reschke, and N. Tellmann, in Proceedings of the 5th Workshop on RF Superconductivity, Hamburg, Germany, 1991, edited by D. Proch (DESY, Hamburg, Germany, 1991), p. 599.

[32] J. Halbritter, in Proceedings of the 2nd Workshop on RF Superconductivity, edited by H. Lengeler (CERN, Geneva, Switzerland, 1984), p. 427.

[33] G. Ciovati and P. Kneisel, Phys. Rev. ST Accel. Beams 9,
042001 (2006).

[34] B. Visentin, J. P. Charrier, Y. Gasser, and S. Regnaud, in Proceedings of the 2006 European Particle Accelerator Conference, Edinburgh, Scotland, 2006, edited by C. Biscari, H. Owen, Ch. Petit-Jean-Genaz, J. Poole, J. Thomason, paper MOPCH141.

[35] Q. Ma, P. Ryan, J. W. Freeland, and R. A. Rosenberg, J. Appl. Phys. 96, 7675 (2004).

[36] C. Z. Antoine, B. Aune, B. Bonin, J. M. Cavedon, M. Juillard, A. Godin, C. Henriot, P. Leconte, H. Safa, and A. Veyssiere, in Proceedings of the 5th Workshop on RF Superconductivity, Hamburg, Germany, 1991, edited by D. Proch (DESY, Hamburg, Germany, 1991), p. 616.

[37] J.-M. Welter and F. J. Johnen, Z. Phys. B 27, 227 (1977).

[38] A. Gurevich, Phys. Rev. B 65, 214531 (2002).

[39] J. Sekutowicz, K. Ko, L. Ge, L. Lee, Z. Li, C. Ng, G. Schussman, L. Xiao, I. Gonin, T. Kabibouline, N. Solyak, Y. Morozumi, K. Saito, and P. Kneisel, in Proceedings of the 2005 Particle Accelerator Conference, Knoxville, 2005, edited by C. Horak (ORNL, Oak Ridge, TN, 2005), p. 3342. 